\title{
Does a similar procedure result in similar survival for women and men undergoing isolated coronary artery bypass grafting?
}

\author{
Tamer Attia, MD, MSc, ${ }^{a}$ Colleen G. Koch, MD, MS, MBA, ${ }^{b}$ Penny L. Houghtaling, MS, \\ Eugene H. Blackstone, MD, ${ }^{\text {add }}$ Ellen Mayer Sabik, MD, ${ }^{\mathrm{c}}$ and Joseph F. Sabik III, MD
}

\section{ABSTRACT}

Objectives: To (1) identify sex-related differences in risk factors and revascularization strategies for patients undergoing coronary artery bypass grafting (CABG), (2) assess whether these differences influenced early and late survival, and (3) determine whether clinical effectiveness of the same revascularization strategy was influenced by sex.

Methods: From January 1972 to January 2011, 57,943 adults-11,009 (19\%) women-underwent primary isolated CABG. Separate models for long-term mortality were developed for men and women, followed by assessing sex-related differences in strength of risk factors (interaction terms).

Results: Incomplete revascularization was more common in men than women (26\% vs $22 \%, P<.0001)$, but women received fewer bilateral internal thoracic artery (ITA) grafts $(4.8 \%$ vs $12 \% ; P<.0001)$ and fewer arterial grafts $(68 \%$ vs $70 \% ; P<.0001)$. Overall, women had lower survival than men after CABG (65\% and $31 \%$ at 10 and 20 years, respectively, vs $74 \%$ and $41 \% ; P \leq .0001$ ), even after risk adjustment. Incomplete revascularization was associated equally $(P>.9)$ with lower survival in both sexes. Single ITA grafting was associated with equally $(P=.3)$ better survival in women and men. Although bilateral ITA grafting was associated with better survival than single ITA grafting, it was less effective in women-11\% lower late mortality (hazard ratio, 0.89 [0.77-1.022]) versus 27\% lower in men (hazard ratio, 0.73 [0.69-0.77]; $P=.01$ ).

Conclusions: Women on average have longer life expectancies than men but not after CABG. Every attempt should be made to use arterial grafting and complete revascularization, but for unexplained reasons, sex-related differences in effectiveness of bilateral arterial grafting were identified. (J Thorac Cardiovasc Surg 2017;153:571-9)

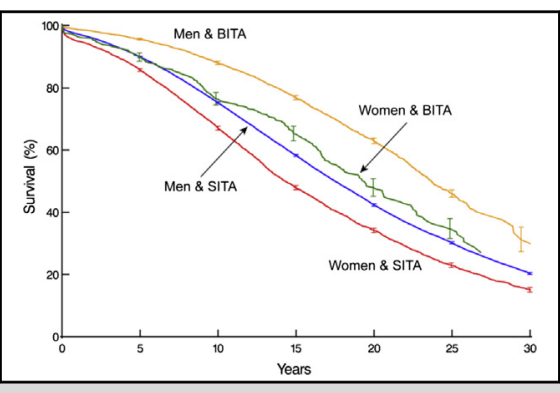

Unadjusted survival after coronary artery bypass grafting stratified by sex and single versus bilateral internal thoracic artery grafting.

\section{Central Message}

Although risk-adjusted survival after coronary artery bypass grafting is worse for women than men, every attempt should be made to fully revascularize all patients undergoing coronary artery bypass grafting and use bilateral internal thoracic artery grafting when possible.

\section{Perspective}

Long-term survival after coronary artery bypass grafting is worse for women than men even after adjustment for differences in strength of risk factors however, in both men and women, complete coronary revascularization and use of bilateral internal thoracic artery grafting are associated with better long-term survival compared with incomplete revascularization and single internal thoracic artery or only saphenous vein grafting.

See Editorial Commentary page 580.
From the Departments of ${ }^{\mathrm{a}}$ Thoracic and Cardiovascular Surgery, ${ }^{\mathrm{b}}$ Cardiothoracic Anesthesia, and ${ }^{\mathrm{c} C}$ ardiovascular Medicine, Heart and Vascular Institute, and ${ }^{\mathrm{d}} \mathrm{De}-$ partment of Quantitative Health Sciences, Research Institute, Cleveland Clinic, Cleveland, Ohio.

This study was supported in part by the Gus P. Karos Registry Fund; the Kenneth Gee and Paula Shaw, PhD, Chair in Heart Research, held by Dr Blackstone; and the Sheikh Hamdan bin Rashid Al Maktoum Distinguished Chair in Thoracic and Cardiovascular Surgery, held by Dr Sabik.

Received for publication July 5, 2016; revisions received Oct 17, 2016; accepted for publication Nov 4, 2016; available ahead of print Jan 17, 2017.

Address for reprints: Joseph F. Sabik III, MD, Chair, Department of Surgery, Surgeonin-Chief and Vice President for Surgical Operations, University Hospitals Cleveland Medical Center, Professor of Surgery, Case Western Reserve University School of Medicine, 11100 Euclid Ave, Lakeside 7/Office 5047, Cleveland, OH 44106-7060 (E-mail: Joseph.Sabik@UHHospitals.org).

$0022-5223 / \$ 36.00$

Copyright (C) 2016 Published by Elsevier Inc. on behalf of The American Association for Thoracic Surgery

http://dx.doi.org/10.1016/j.jtcvs.2016.11.033
If the same operation for coronary artery disease were performed in women and men with the same comorbidities and extent of coronary artery disease, would outcomes be the same? Women undergoing coronary artery bypass grafting (CABG) generally are older and sicker than men and have a disproportionate number of risk factors associated with poor outcomes ${ }^{1-4}$; however, depending on the statistical approach, richness of the

Scanning this QR code will take you to supplemental figures, tables, and appendix for this article.

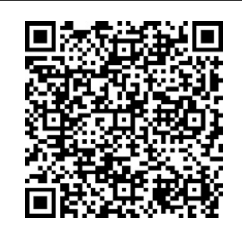




\section{Abbreviations and Acronyms \\ $\mathrm{CABG}=$ coronary artery bypass grafting \\ ITA = internal thoracic artery \\ LAD = left anterior descending coronary artery \\ SVG $=$ saphenous vein graft}

data set, and length of follow-up, studies differ on whether their outcomes after CABG are worse than those of men, all else being equal. ${ }^{1,2,5}$

Although few sex-specific preoperative risk factors potentially are modifiable, surgeons can influence sex-specific variation in factors related to decisions about revascularization strategy, such as completeness of coronary revascularization and choice of bypass conduits. ${ }^{6}$ What is uncertain, however, is whether a similar revascularization approach for similar coronary artery disease in a woman and a man with similar comorbidities results in similar outcomes.

Therefore, our objectives were to (1) identify sex-associated differences in preoperative risk factors and revascularization strategies; (2) assess whether these differences, particularly in revascularization strategy, influence risk-adjusted early and late mortality; and (3) determine whether clinical effectiveness of the same revascularization strategy is influenced by sex.

\section{PATIENTS AND METHODS \\ Patients}

From January 1972 to January 2011, 57,943 adults, including 11,009 women $(19 \%)$, underwent primary isolated CABG at Cleveland Clinic. Preoperative, operative, and postoperative variables were retrieved from the Cardiovascular Information Registry of the Heart and Vascular Institute. This registry is populated concurrently with patient care and has been approved for use in research by the institutional review board, with individual patient consent waived.

\section{Revascularization Strategies}

Completeness of revascularization was defined as a conduit placed to any coronary system (left anterior descending coronary artery [LAD], left circumflex coronary artery [LCx], or right coronary artery systems) with $50 \%$ or more stenosis, or grafting to both the LAD and LCx systems for left main disease $\geq 50 \%$. Surgical revascularization strategies included the following main conduits: saphenous vein graft (SVG), single or bilateral internal thoracic artery graft, and radial artery graft.

\section{Endpoints}

In-hospital safety endpoints included those defined and assessed as quality benchmarks by the Society of Thoracic Surgeons National Database (see http://www.sts.org/sites/default/files/documents/STSAdultCV DataSpecificationsV2 _81.pdf). The effectiveness endpoint was all-cause time-related mortality and its instantaneous risk; all-cause mortality is a hard endpoint not subject to subjective interpretation. Systematic periodic follow-up data were obtained through the Cardiovascular Information Registry through year 2000, supplemented with information from the Social Security Death Master File, accessed on October 27,
2011, when it still contained all federal and state death records. To account for a reporting lag time of 6 months, a closing date of April 27, 2011, was used.

Median follow-up for women was 10 years; $25 \%$ of survivors were followed more than 19 years and $10 \%$ more than 27 years, with 126,462 patient-years of follow-up data available for analysis. Median follow-up for men was 12 years; $25 \%$ of survivors were followed more than 22 years and $10 \%$ more than 31 years, with 626,162 patient-years of follow-up data available for analysis.

\section{Data Analysis}

Analyses were performed with SAS version 9.2 statistical software (SAS Institute, Inc, Cary, NC).

Sex differences in preoperative characteristics, revascularization strategy, and in-hospital outcomes. Comparisons of preoperative characteristics, revascularization strategies, and in-hospital outcomes between women and men were made with the Wilcoxon ranksum nonparametric test for continuous variables, and the $\chi^{2}$ test (Fisher exact test when frequency was $<5$ ) for categorical variables. $P \leq .05$ was considered a statistically significant difference. Logistic regression analysis was performed for hospital mortality by using variables in Appendix E1 and bootstrap variable selection. ${ }^{7}$ Briefly, with a $P$-value criterion for retention of variables in the model of .05 , variables from 500 resampled data sets with bootstrap reliability of $50 \%$ or more were included in the parsimonious model.

Sex differences in survival. Nonparametric survival estimates stratified by sex and revascularization strategy were obtained by using the Kaplan-Meier method and parametric estimates via a multiphase nonproportional hazards model. ${ }^{8}$ The parametric method was used to resolve the number of phases of instantaneous risk of death (hazard function) and to estimate shaping parameters (for details, see www.lerner.ccf.org/ qhs/software/hazard), because there was a short early period of elevated risk followed by a gradually rising late risk of death. These different phases of risk, labeled early and late (Figure E1), were data driven, resolved by temporal decomposition. Because of the orthogonal nature of such decompositions, separate streams of covariables were analyzed simultaneously in the same model. ${ }^{8}$ Because the shape of time-varying risk of death could differ for women and men, we constructed separate hazard models for each, as well as for the combined group. Survival estimates of matched US populations were generated for each patient from US life tables and according to age, sex, and race, then averaged.

Multivariable analysis was performed in the hazard function domain, incorporating variables simultaneously into all phases using those listed in Appendix E1, with bootstrap variable selection as described in the previous text.

Women presenting for $\mathrm{CABG}$ were more symptomatic than men and more prone to have heart failure, hypertension, peripheral arterial and cerebrovascular disease, and pharmacologically treated diabetes (Table 1). By contrast, men had more diseased coronary arteries, previous myocardial infarctions, and a history of smoking. Therefore, the modeling strategy was as follows: Separate parsimonious models were developed for women and men, each in 3 steps: (1) preoperative factors only, (2) procedure-related and revascularization strategies only, and (3) preoperative and procedure/ revascularization variables combined. Thereafter, a semisaturated model was created that included every variable identified either in the female or male model and an interaction term for each with female sex to determine female-male differences in risk-factor strength and statistical significance.

To test the global effect of female sex on survival, we created a nested model by excluding the variable "female" and all female-variable interactions from the semisaturated model. We then compared the log-likelihood of the nested models. 
TABLE 1. Patient characteristics stratified by sex $(n=57,943)$

\begin{tabular}{|c|c|c|c|c|c|}
\hline \multirow[b]{2}{*}{ Variable } & \multicolumn{2}{|c|}{$\operatorname{Men}(n=46,934)$} & \multicolumn{2}{|c|}{ Women $(n=11,009)$} & \multirow[b]{2}{*}{$P$} \\
\hline & $\mathbf{n}^{*}$ & No. $(\%)$ or Mean \pm SD & $\mathbf{n}^{*}$ & No. $(\%)$ or Mean \pm SD & \\
\hline \multicolumn{6}{|l|}{ Demographics } \\
\hline Age, y & 46,934 & $59 \pm 10$ & 11,009 & $64 \pm 10$ & $<.0001$ \\
\hline Body mass index, $\mathrm{kg} \cdot \mathrm{m}^{-2}$ & 29,431 & $28 \pm 4.7$ & 8434 & $28 \pm 6.0$ & .4 \\
\hline \multicolumn{6}{|l|}{ Race } \\
\hline White & 42,952 & $39,603(92)$ & 10,408 & $9477(91)$ & .0001 \\
\hline Black & 42,952 & $1032(2.4)$ & 10,408 & $631(6.1)$ & $<.0001$ \\
\hline Other & 42,952 & $2317(5.4)$ & 10,408 & $300(2.9)$ & $<.0001$ \\
\hline \multicolumn{6}{|l|}{ Acuity } \\
\hline NYHA functional class & 46,534 & & 10,944 & & $<.0001$ \\
\hline I & & $8172(18)$ & & $1624(15)$ & \\
\hline II & & $18,045(39)$ & & $3386(31)$ & \\
\hline III & & 4934 (11) & & $1487(14)$ & \\
\hline IV & & $15,383(33)$ & & $4447(41)$ & \\
\hline Emergency operation & 46,933 & $1125(2.4)$ & 11,008 & $448(4.1)$ & $<.0001$ \\
\hline \multicolumn{6}{|l|}{ Coronary artery disease $\dagger$} \\
\hline LMT & 43,524 & $6952(16)$ & 9905 & $1816(18)$ & $<.0001$ \\
\hline LAD & 44,859 & $41,414(92)$ & 10,340 & $9365(91)$ & $<.0001$ \\
\hline $\mathrm{LCx}$ & 44,606 & $32,630(73)$ & 10,230 & $6937(68)$ & $<.0001$ \\
\hline $\mathrm{RCA}$ & 44,651 & $36,607(82)$ & 10,250 & $8238(80)$ & .0001 \\
\hline \multicolumn{6}{|l|}{ Cardiac comorbidity } \\
\hline Preoperative AF or flutter & 37,430 & $473(1.3)$ & 9407 & $123(1.3)$ & .7 \\
\hline Heart failure & 46,932 & $2750(5.9)$ & 11,009 & $1318(12)$ & $<.0001$ \\
\hline Previous myocardial infarction & 46,934 & $24,604(52)$ & 11,009 & $5426(49)$ & $<.0001$ \\
\hline LV dysfunction & 43,738 & & 9938 & & $<.0001$ \\
\hline None & & $37,164(85)$ & & $8112(82)$ & \\
\hline Mild & & $2835(6.5)$ & & $751(7.6)$ & \\
\hline Moderate & & $2215(5.1)$ & & $656(6.6)$ & \\
\hline Severe & & $1524(3.5)$ & & $419(4.3)$ & \\
\hline \multicolumn{6}{|l|}{ Noncardiac comorbidity } \\
\hline Peripheral arterial disease & 46,934 & $4905(10)$ & 11,009 & 1725 (16) & $<.0001$ \\
\hline Hypertension & 16,468 & $11,283(69)$ & 5328 & $4304(81)$ & $<.0001$ \\
\hline Previous stroke & 46,933 & $1788(3.8)$ & 11,009 & $686(6.2)$ & $<.0001$ \\
\hline Pharmacologically treated diabetes & 44,865 & $7246(16)$ & 10,619 & $3110(29)$ & $<.0001$ \\
\hline History of smoking & 45,114 & $25,315(56)$ & 10,731 & $4961(46)$ & $<.0001$ \\
\hline Chronic obstructive pulmonary disease & 16,468 & $1190(7.2)$ & 5328 & $446(8.4)$ & .006 \\
\hline Bilirubin, $\mathrm{mg} \cdot \mathrm{dL}^{-1}$ & 14,359 & $0.66 \pm 0.50$ & 4563 & $0.52 \pm 0.47$ & $<.0001$ \\
\hline Creatinine, $\mathrm{mg} \cdot \mathrm{dL}^{-1}$ & 15,977 & $1.2 \pm 0.92$ & 5181 & $1.1 \pm 1.05$ & $<.0001$ \\
\hline Renal dialysis & 8736 & $101(1.2)$ & 2916 & $57(2.0)$ & .001 \\
\hline Cholesterol & 35,480 & $228 \pm 56$ & 7658 & $240 \pm 66$ & $<.0001$ \\
\hline Triglycerides, $\mathrm{mg} \cdot \mathrm{dL}^{-1}$ & 29,970 & $188 \pm 128$ & 6368 & $190 \pm 131$ & .8 \\
\hline Hematocrit & 14,791 & $41 \pm 5.0$ & 4799 & $36 \pm 4.8$ & $<.0001$ \\
\hline
\end{tabular}

$S D$, Standard deviation; NYHA, New York Heart Association; $L M T$, left main trunk; $L A D$, left anterior descending coronary artery; $L C x$, left circumflex coronary artery; $R C A$, right coronary artery; $A F$, atrial fibrillation; $L V$, left ventricular. *Patients with data available. $†$ Stenosis $\geq 50 \%$.

Missing values. To account for missing values for some covariables in the multivariable analysis, 5-fold multiple imputation was performed using the Markov chain Monte Carlo technique (SAS PROC MI and PROC MIANALYZE). ${ }^{9}$

Presentation. Categorical variables are summarized as frequencies and percentages, and continuous variables as mean \pm standard deviation or 15th, 50th (median), and 85th percentiles when distributions are skewed. Transformation of scale of continuous variables was necessary to meet statistical model assumptions; therefore, results of the multiphase hazard models are presented with their coefficients, rather than hazard ratios.
Survival results are depicted with simple Kaplan-Meier stratifications according to sex; however, to illustrate risk-adjusted effects of revascularization strategy on survival, the semisaturated multivariable hazard model was solved for a typical female profile. Specifically, except for the variable being illustrated, model variables were fixed at the following values: age 65 years, body mass index $27 \mathrm{~kg} \cdot \mathrm{m}^{-2}$, white race, New York Heart Association functional class III/IV, 3-system disease (maximum LAD stenosis $90 \%$, maximum LCx stenosis $75 \%$, maximum right coronary artery stenosis $90 \%$ ), peripheral arterial disease, pharmacologically treated diabetes, preoperative creatinine $1.2 \mathrm{mg} \cdot \mathrm{dL}^{-1}$, preoperative cholesterol $236 \mathrm{mg} \cdot \mathrm{dL}^{-1}$, preoperative 
triglycerides $159 \mathrm{mg} \cdot \mathrm{dL}^{-1}$, preoperative hematocrit $40 \%$, complete revascularization with $\geq 50 \%$ stenosis, and any intraoperative or preoperative blood products given.

\section{RESULTS}

\section{Sex Differences in Revascularization Strategies}

Incomplete revascularization was more common in men than women (Table 2); however, women received fewer arterial grafts, including less use of bilateral internal thoracic artery (ITA) grafts (Figure E2) and radial artery grafts than men, less use of total arterial revascularization, and greater use of SVGs to the LAD. They also were more likely to receive only SVGs for revascularization. The majority of operations for both women and men were performed with cardiopulmonary bypass, but more women had off-pump procedures.

\section{Sex Differences in In-Hospital Outcomes}

Although occurring infrequently, postoperative deep sternal wound infections and septicemia occurred more often in women than men, and women experienced more postoperative strokes, renal failure, and renal failure requiring dialysis (Table 3). They also experienced newonset atrial fibrillation more often and had more prolonged ( $>24$ hours) postoperative mechanical ventilation. Women also had longer intensive care unit and postoperative lengths of stay. There was no significant difference in the occurrence of perioperative myocardial infarction. In-hospital mortality was greater for women than men even after risk adjustment (Table 3 and Table E1).

\section{Sex Differences in Time-Related Survival}

Overall, women had lower time-related survival than men after CABG (Figure 1), and this has persisted since the beginning of CABG at Cleveland Clinic (Figure E3). Consequently, the gap between survival of women in the general population and women after $\mathrm{CABG}$ was wider than that for men. After we adjusted for patient and revascularization strategy differences, female sex remained an independent risk factor for death overall $(P<.0001)$ and

TABLE 2. Procedural details stratified by sex $(n=57,943)$

\begin{tabular}{|c|c|c|c|c|c|}
\hline \multirow[b]{2}{*}{ Variable } & \multicolumn{2}{|c|}{$\operatorname{Men}(n=46,934)$} & \multicolumn{2}{|c|}{ Women $(n=11,009)$} & \multirow[b]{2}{*}{$\boldsymbol{P}$} \\
\hline & $\mathbf{n}^{*}$ & No. $(\%)$ or mean \pm SD & $\mathbf{n}^{*}$ & No. $(\%)$ or mean \pm SD & \\
\hline \multicolumn{6}{|l|}{ CABG details } \\
\hline \multicolumn{6}{|l|}{ Grafts } \\
\hline ITA & 46,934 & & 11,009 & & $<.0001$ \\
\hline 0 & & $14,090(30)$ & & $3590(33)$ & \\
\hline 1 & & $27,246(58)$ & & $6890(63)$ & \\
\hline 2 & & $5598(12)$ & & $529(4.8)$ & \\
\hline Radial artery & 46,934 & $2852(6.1)$ & 11,009 & $495(4.5)$ & $<.0001$ \\
\hline All arterial grafts & 46,934 & $4356(9.3)$ & 11,009 & $927(8.4)$ & .005 \\
\hline Saphenous vein & 46,934 & $42,574(91)$ & 11,009 & $10,077(92)$ & .007 \\
\hline Saphenous vein only & 46,934 & $14,036(30)$ & 11,009 & $3568(32)$ & $<.0001$ \\
\hline Grafting strategy to LAD & 46,934 & $42,419(90)$ & 11,009 & $9966(91)$ & .6 \\
\hline ITA & 42,419 & $30.371(72)$ & 9966 & $6903(69)$ & $<.0001$ \\
\hline SVG & 42,419 & $12,289(29)$ & 9966 & $3122(31)$ & $<.0001$ \\
\hline Grafting strategy to $\mathrm{LCx}$ & 46,934 & $35,047(75)$ & 11,009 & $7837(71)$ & $<.0001$ \\
\hline ITA & 35,047 & 4927 (14) & 7837 & $510(6.5)$ & $<.0001$ \\
\hline SVG & 35,047 & $30,046(86)$ & 7837 & $7161(91)$ & $<.0001$ \\
\hline Grafting strategy to RCA & 46,934 & $30,744(66)$ & 11,009 & $7473(68)$ & $<.0001$ \\
\hline ITA & 30,744 & $1325(4.3)$ & 7473 & $185(2.5)$ & $<.0001$ \\
\hline SVG & 30,744 & $28,703(93)$ & 7473 & $7168(96)$ & $<.0001$ \\
\hline \multicolumn{6}{|l|}{ Completeness of revascularization $\dagger$} \\
\hline Incomplete revascularization & 46,934 & $12,017(26)$ & 11,009 & $2388(22)$ & $<.0001$ \\
\hline LMT & 46,934 & $599(1.3)$ & 11,009 & $196(1.8)$ & $<.0001$ \\
\hline LAD & 46,934 & $1109(2.4)$ & 11,009 & $213(1.9)$ & .007 \\
\hline $\mathrm{LCx}$ & 46,934 & $3643(7.8)$ & 11,009 & $824(7.5)$ & .3 \\
\hline RCA & 46,934 & $8216(18)$ & 11,009 & $1446(13)$ & $<.0001$ \\
\hline \multicolumn{6}{|l|}{ Support } \\
\hline Off-pump revascularization & 49,934 & $1375(2.9)$ & 11,009 & $601(5.4)$ & $<.0001$ \\
\hline Cardiopulmonary bypass & 46,934 & $45,559(97)$ & 11,009 & $10,408(95)$ & $<.0001$ \\
\hline Cardiopulmonary bypass time, $\min$ & 11,917 & $97 \pm 32$ & 3762 & $92 \pm 32$ & $<.0001$ \\
\hline Myocardial ischemic time, $\min$ & 13,332 & $64 \pm 32$ & 4345 & $57 \pm 32$ & $<.0001$ \\
\hline
\end{tabular}

$S D$, Standard deviation; $C A B G$, coronary artery bypass grafting; $I T A$, internal thoracic artery; $L A D$, left anterior descending coronary artery; $S V G$, saphenous vein graft; $L C x$, left circumflex coronary artery; $R C A$, right coronary artery; $L M T$, left main trunk. *Patients with data available or applicable. $\dagger \geq 50 \%$ stenosis. 
TABLE 3. In-hospital outcomes $(n=57,943)$

\begin{tabular}{|c|c|c|c|c|c|}
\hline \multirow[b]{2}{*}{ Outcome } & \multicolumn{2}{|c|}{$\operatorname{Men}(n=46,934)$} & \multicolumn{2}{|c|}{ Women $(n=11,009)$} & \multirow[b]{2}{*}{$\boldsymbol{P}$} \\
\hline & $\mathbf{n}^{*}$ & No. $(\%)$ & $\mathbf{n}^{*}$ & No. $(\%)$ & \\
\hline Hospital death & 46,934 & $510(1.1)$ & 11,009 & $293(2.7)$ & $<.0001$ \\
\hline Atrial fibrillation & 46,934 & 6065 (13) & 11,009 & $1628(15)$ & $<.0001$ \\
\hline Prolonged ventilation (>24 h) & $4272 \dagger$ & $393(9.2)$ & 1407 & $189(13)$ & $<.0001$ \\
\hline Reoperation for bleeding/tamponade & 46,934 & $1858(4.0)$ & 11,009 & $386(3.5)$ & .03 \\
\hline Septicemia & $16,468 \dagger$ & $265(1.6)$ & 5328 & $126(2.4)$ & .0003 \\
\hline Deep sternal wound infection & 44,862 & $573(1.3)$ & 10,619 & $191(1.8)$ & $<.0001$ \\
\hline Permanent stroke & 46,934 & $647(1.4)$ & 11,009 & $254(2.3)$ & $<.0001$ \\
\hline Perioperative myocardial infarction & 46,934 & $977(2.1)$ & 11,009 & $240(2.2)$ & .5 \\
\hline Renal failure requiring dialysis & $16,468 \dagger$ & $118(0.72)$ & 5328 & $75(1.4)$ & $<.0001$ \\
\hline \multicolumn{6}{|l|}{ Length of stay } \\
\hline ICU, h & $16,466 \dagger$ & $24 / 24 / 72 \ddagger$ & 5326 & $24 / 30 / 96 \ddagger$ & $<.0001$ \\
\hline Postoperative, $\mathrm{d}$ & 45,811 & $6 / 8 / 10_{\ddagger}^{\ddagger}$ & 10,843 & $6 / 8 / 12 \ddagger$ & $<.0001$ \\
\hline
\end{tabular}

$I C U$, Intensive care unit. *Patients with data available. $\nmid$ Recently recorded outcomes. $\ddagger 15$ th $/ 50$ th/ $/ 85$ th percentiles. Median score test was used to compare medians and Wilcoxon rank-sum test to compare tails of distributions. $P$ values are given for median score test.

both early $(P<.0001)$ and late $(P=.01)$ after CABG (Tables E2 and E3).

\section{Effectiveness of Revascularization Strategies}

Incomplete revascularization was associated with lower survival than complete revascularization in both men and women, with incompletely revascularized women having the worst survival $-81 \%$ versus $87 \%, 58 \%$ versus $70 \%$, and $25 \%$ versus $35 \%$ at 5,10 , and 20 years, respectively (Figure 2, A). Although risk-adjusted nomograms show considerable narrowing of these differences, the relationships to survival remained the same, without a differential effect attributable to sex $(P>.9$; Figures $2, B$, and 3, Tables E2 and E3).

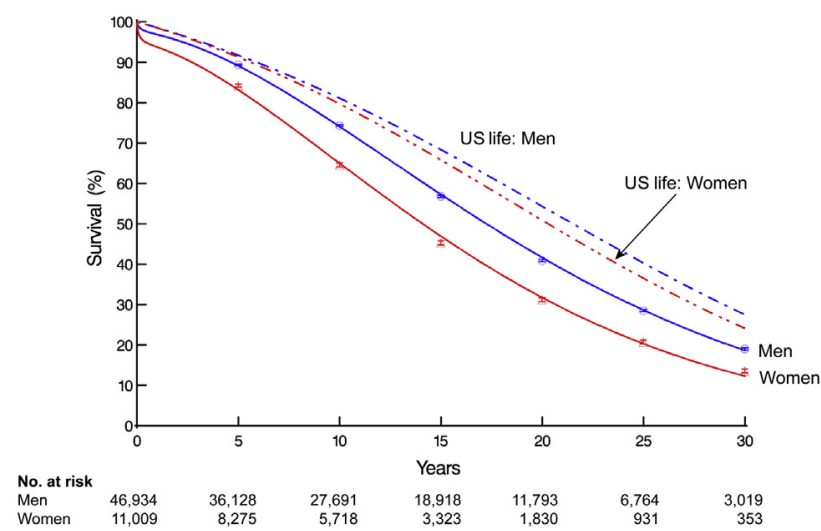

FIGURE 1. Survival after cardiac surgery in men and women. Symbols represent Kaplan-Meier estimates at 5-year intervals and vertical bars confidence limits equivalent to \pm 1 standard error. Solid curves are parametric survival estimates. Red lines and triangles represent women and blue lines and circles men. Dash-dot-dash lines are age-sex-race-matched survival estimates for the US population. Number of patients remaining at risk at 5 -year intervals is shown beneath the horizontal axis.
Use of ITA grafts was associated with better survival than use of SVGs alone and was best when bilateral ITA grafting was performed (Figure 3, Tables E2 and E3). Women receiving SVGs alone had the lowest survival, $80 \%$, $58 \%$, and $25 \%$ at 5,10 , and 20 years, respectively (Figure $4, A$ ), compared with $86 \%, 68 \%$, and $33 \%$ for men (Figure $4, B$ ). Men with bilateral ITA grafts had the highest survival, $96 \%, 88 \%$, and $63 \%$ at 5,10 , and 20 years, respectively, compared with $90 \%, 77 \%$, and $48 \%$ for women (Figure 4, $C$ and Figure 5). Women who received bilateral ITA grafting appeared to have survival similar to that of men after single ITA grafting $(P=.12$ after multivariable adjustment; Figure $4, D$ ). Non-risk-adjusted actuarial estimates demonstrate that these relationships have been consistent across time (Figure E4).

\section{DISCUSSION}

Worse outcomes after CABG in women compared with men have been attributed to older age, delayed diagnosis and treatment, greater prevalence of comorbidities (respiratory disease, diabetes, hypertension, and heart failure), smaller size, more acute presentation, underuse of arterial grafts (specifically the ITA), and referral bias. ${ }^{3,5,10}$ These differences make it difficult to determine whether women's worse outcomes are related solely to a greater preoperative risk profile or to a less-than-ideal operation. Hence, in this study we used extensive risk adjustment to examine the association of these differences in revascularization strategies between male and female patients with survival after $\mathrm{CABG}$.

\section{Principal Findings}

Women had less favorable preoperative characteristics than men, but received fewer bilateral ITA grafts and less all-arterial grafting as part of their revascularization strategy. Women also experienced greater morbidity and greater 

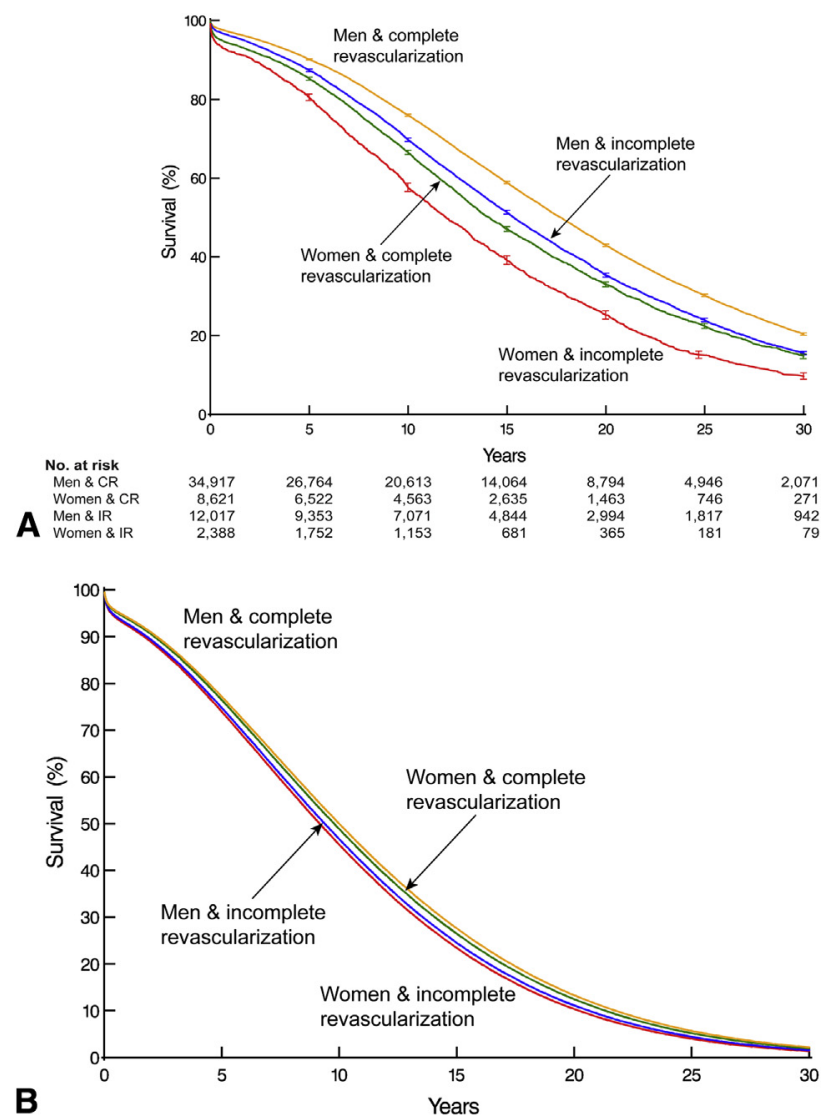

FIGURE 2. Survival after coronary artery bypass grafting stratified by sex and completeness of revascularization. A, Unadjusted Kaplan-Meier estimates, with confidence limits equivalent to \pm 1 standard error shown as vertical bars at 5-year intervals. Number of patients remaining at risk at 5-year intervals is shown beneath horizontal axis. B, Adjusted. Nomogram for survival of a patient with typical female characteristics based on the multivariable model (Tables E2 and E3), with variables held constant, as noted in the Methods. Single internal thoracic artery grafting is simulated for both men and women. $C R$, Complete revascularization; $I R$, incomplete revascularization.

in-hospital mortality after CABG than men. Unlike the general population, they had lower risk-adjusted long-term survival than men, with the worst survival noted in women who were incompletely revascularized and had no ITA grafting, and the best in men who were completely revascularized and had bilateral ITA grafting. The effectiveness of bilateral ITA grafting, however, was blunted in women compared with men.

\section{Sex Differences in Revascularization Strategies}

Our finding of less use of arterial conduits in women is consistent with results of other studies. ${ }^{11,12}$ In a study of 1758 patients undergoing primary isolated CABG between 2003 and 2005 that included 398 women $(23 \%)$ and 1360 men $(77 \%)$, Sharoni and colleagues ${ }^{13}$ found similar use of left ITA grafts (men, 99\%; women, 98\%;

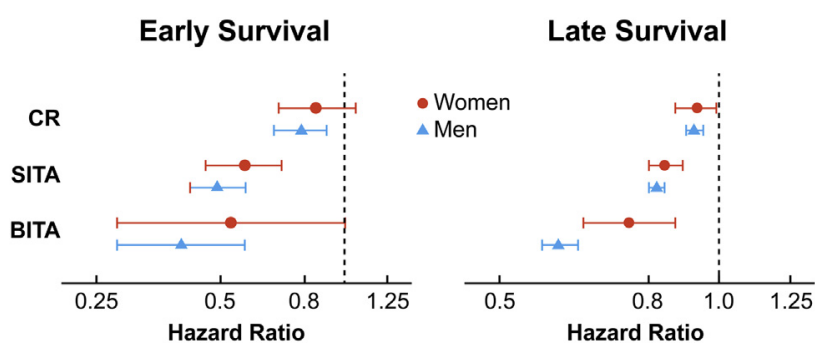

FIGURE 3. Forest plot of early and late survival after coronary artery bypass grafting according to revascularization strategy, adjusted for differences in characteristics between women and men. Symbols represent the hazard ratio and horizontal bars $95 \%$ confidence limits. Note difference in horizontal scales. $C R$, Complete revascularization; SITA, single internal thoracic artery grafting; BITA, bilateral internal thoracic artery grafting.

$P=.2$ ) and radial artery grafts (men, $49 \%$; women, $59 \% ; P=.12)$ in both sexes. However, women received fewer right ITA grafts (women, 15\%; men, 33\%; $P<.01$ ). Among 374,918 Medicare beneficiaries aged 66 years or older who underwent isolated multivessel CABG between 1988 and 2008, Hlatky and colleagues ${ }^{14}$ found that ITA use increased from $31 \%$ in 1988 to $91 \%$ in 2008. However, ITA use remained lower in women $(32 \%)$ than men $(42 \%)$ in $2008(P=.04)$.

\section{Sex Differences in In-Hospital Outcomes}

In this study, unadjusted analysis showed greater morbidity and higher in-hospital mortality for women, and this difference was not explained by their different comorbidity profile, in contrast to what has been reported previously. ${ }^{2,10,15}$ Our previous work showed similar in-hospital mortality among well-matched women and men $^{2}$; however, in that study, only $26 \%$ of women could be matched with men, reflecting the marked dissimilarity between the sexes in baseline preoperative characteristics. Despite a higher overall morbidity, less complete revascularization, and more SVG use in women, occurrence of perioperative myocardial infarction was similar for both women and men.

\section{Sex Differences in Long-Term Survival}

We found lower unadjusted and risk-adjusted survival in women than men, and this has been consistent in our experience since the beginning of CABG. Other reports of longterm survival of women after CABG are inconsistent. ${ }^{15-18}$ It was in part the discrepancies in these findings that stimulated us to approach our study differently from those of the past. We did not focus on an overall result, as is the forte of a propensity-matching approach. Rather, we identified risk factors for death separately for women and men to establish a pool of factors. Then we looked for interactions - different strengths of association of these factors between women and men. This strategy highlights not only the 

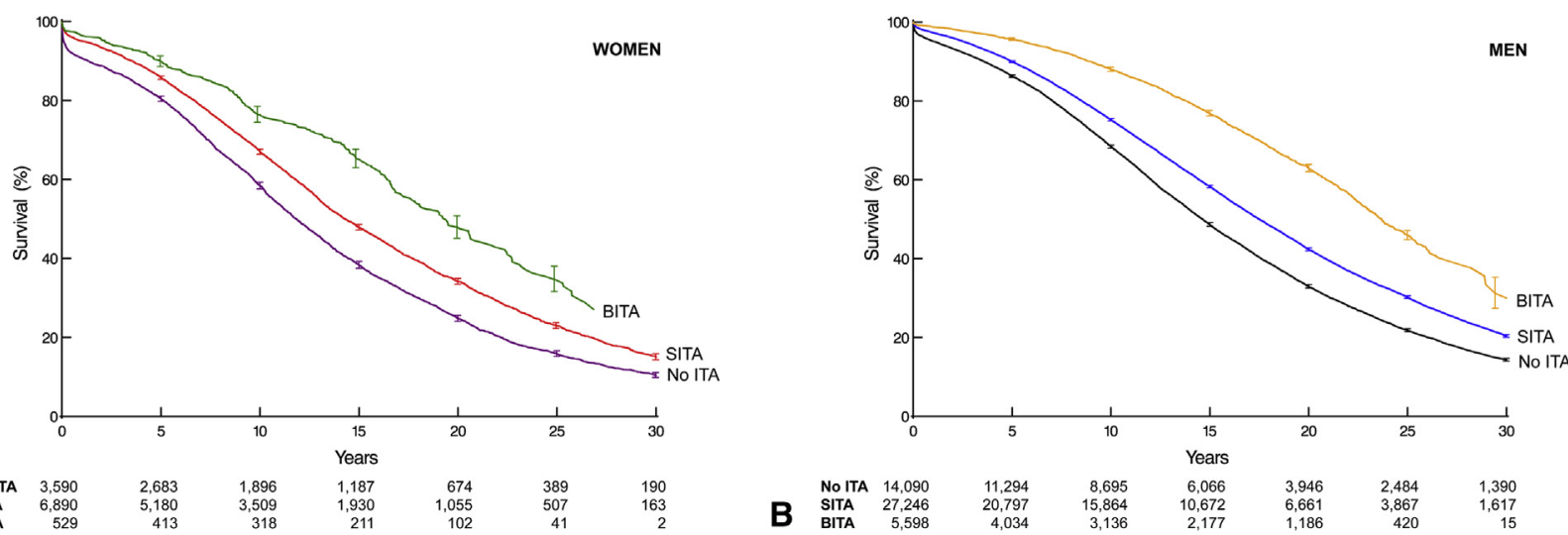

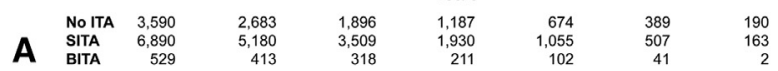
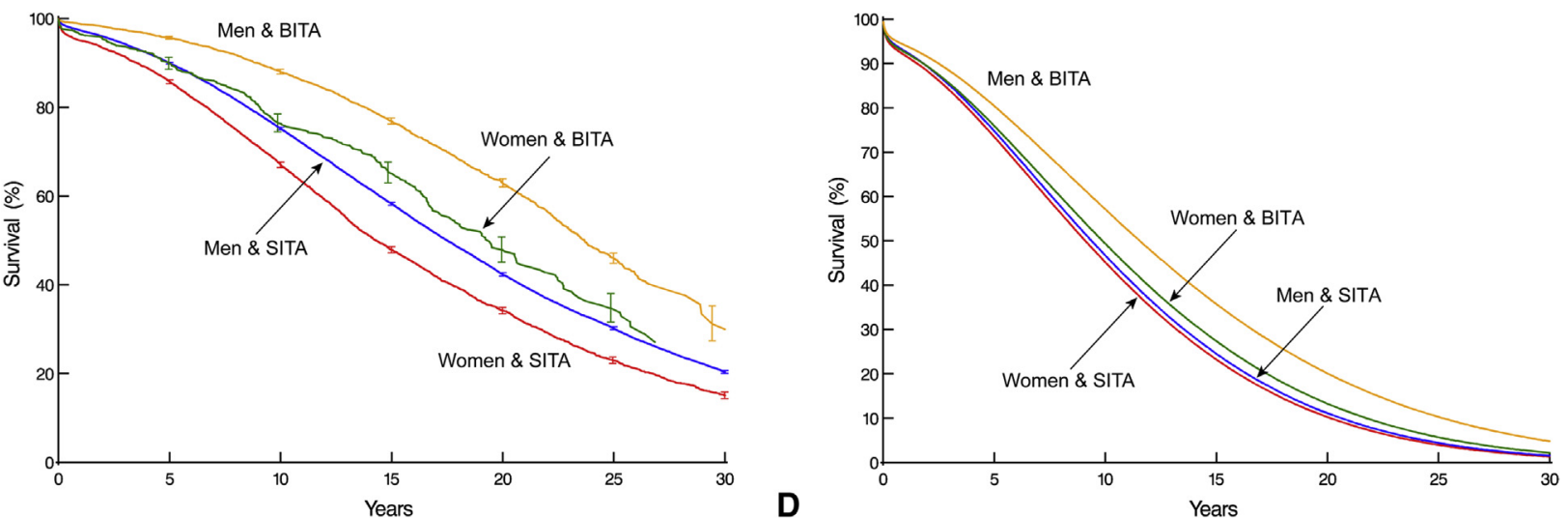

FIGURE 4. Survival after coronary artery bypass grafting stratified by sex and single versus bilateral internal thoracic artery grafting. BITA, Bilateral internal thoracic artery grafting; SITA, single internal thoracic artery grafting. A, Women. Format is as in Figure 2, A. B, Men. Format is as in Figure 2, A. C, Unadjusted. Format for Kaplan-Meier estimates is as in Figure 2, A. D, Adjusted. Variables as in Figure 2, $B$ except that complete revascularization with $\geq 50 \%$ stenosis was simulated for both men and women.

risk factors for death, but also how they may affect survival differently in women and men.

It is possible that the discrepancies arise because allcause mortality is an incomplete metric of outcome. For

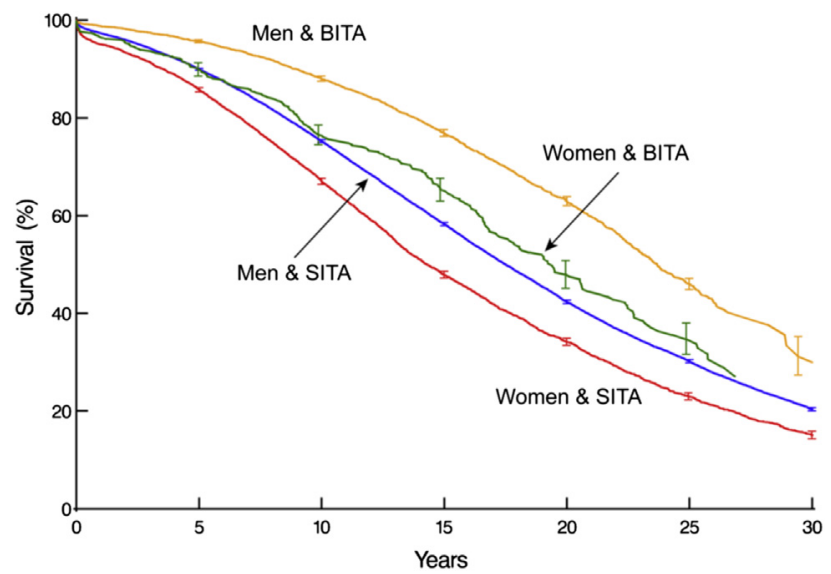

FIGURE 5. Unadjusted survival after coronary artery bypass grafting stratified by sex and single versus bilateral internal thoracic artery grafting. example, Vaccarino and colleagues ${ }^{19}$ found that after CABG, women showed less improvement in physical functioning than men. Less-favorable gains in functional status could be related to differences in revascularization strategies, such as less complete revascularization, or to more graft occlusions. ${ }^{18,20,21}$ Abramov and colleagues ${ }^{11}$ attributed the higher prevalence of recurrent postoperative angina in women than in men after CABG to incomplete revascularization, graft occlusion, and progressive atherosclerosis, although they found no sex-related difference in performance of repeat revascularization. Kurlansky and colleagues $^{22}$ reported greater risk of late myocardial infarction among women than propensity-matched men, all of whom received bilateral ITA grafts.

\section{Effectiveness of Revascularization Strategies}

We found that complete revascularization in both women and men was associated with better survival than incomplete revascularization. This finding is consistent with previous reports of decreased survival and increased adverse events with incomplete revascularization. ${ }^{23,24}$ 
The survival benefit associated with use of ITA grafting is well established. ${ }^{25,26}$ Similarly, use of more arterial conduits has been associated with decreased in-hospital and late mortality and lower recurrence of angina. ${ }^{27,28}$ However, although bilateral ITA use in women was associated with possibly better survival than single ITA grafting, it was only half as effective as in men. Why would women have different survival than men after bilateral ITA grafting? We hypothesize that this difference may be related to smaller coronary arteries, more diffuse coronary artery disease, and smaller arterial grafts in women. These factors could result in reduced effectiveness of arterial revascularization and possibly decreased graft patency.

In support of this hypothesis, Douglas and colleagues ${ }^{29}$ reported that women had smaller coronary arteries and reduced graft patency compared with men. Roberts and Roberts $^{30}$ reported smaller cross-sectional area of the proximal coronary arteries in women that they attributed to differences in body weight and heart size, but others have found that these differences persisted after accounting for body size. ${ }^{31,32}$ Grafting small coronary arteries is associated with limitation of conduit flow, which correlates with increased operative mortality after CABG, even after adjusting for preoperative variables. ${ }^{31,33}$ Women also have higher rates of admission for recurrent angina and heart failure than men, ${ }^{20,34}$ but tend to have less extensive coronary artery disease and less collateral circulation. ${ }^{34,35}$

Why did we find reduced effectiveness of bilateral, but not single, ITA grafting in women? The answer is unclear, although the left ITA is most commonly used to bypass LAD lesions, whereas the right ITA usually is used to bypass the second most important target, which is likely to be smaller than the left ITA target.

\section{Clinical Implications}

Although 2 ITA grafts are better than 1 for both women and men, bilateral grafting appears less effective in women in the long term. Hence, a patient's sex deserves special consideration in operative planning. Would a more meticulous harvesting of conduits and better coronary target selection narrow the outcome gap between men and women? How effective are the procedures currently in use? Is there a specific group of women who benefit more from bilateral ITA grafting and who are less susceptible to the risk of sternal wound infections? Identifying such a group of patients could increase appropriate use of bilateral ITA grafting.

\section{Strengths and Limitations}

This is a single-institution prospective cohort investigation in which unaccounted-for variables could have influenced outcomes. However, because of the inability to randomize sex, our study is a natural experiment. We considered variables known to be related to early and late mortality in this patient population. Factors related to surgeons' decision-making about choice of conduit, and whether the predetermined revascularization strategy ultimately was performed, modified, or abandoned secondary to untoward intraoperative circumstances (eg, poor conduit after harvest), are unknown. In addition, our follow-up focused on all-cause long-term mortality. Although this is a hard endpoint, fatal and nonfatal myocardial infarction, stroke, need for repeat revascularization, compliance with rehabilitation, medications, and diet were not studied. Incomplete revascularization can be attributed to poor coronary targets versus surgeon choice; we were unable to distinguish between the 2 from our database.

A considerable strength of the study is that it spans 4 decades, permitting us to assess long-term mortality consequences of the initial revascularization strategy; indeed, this is the only way to obtain long-term information. At the same time, the 4-decade span introduces limitations. Thus, early outcomes (Tables E4 and E5) and late survival might have been influenced by changes in patient characteristics (Figure E5) and advances in both initial and longitudinal medical treatment, such as postoperative use of statins and antiplatelet medications, and intervention techniques, although these changes are likely to have influenced both sexes. We have demonstrated that sex differences in survival and differences with respect to revascularization strategy associated with long-term survival have been present in our experience since the beginning of CABG.

\section{CONCLUSIONS}

Every attempt should be made to achieve complete coronary revascularization and use arterial grafting in both women and men. The difference in effectiveness of bilateral ITA grafting needs to be considered in women at elevated risk for bilateral ITA harvesting complications.

\section{Conflict of Interest Statement}

Dr Sabik is the North American principal investigator for the Abbott Laboratories-sponsored left main coronary disease randomized trial (EXCEL), is on the Society of Thoracic Surgeons board of directors, and is on the scientific advisory board of Medtronic. All other authors have nothing to disclose with regard to commercial support.

\section{References}

1. Guru V, Fremes SE, Tu JV. Time-related mortality for women after coronary artery bypass graft surgery: a population-based study. J Thorac Cardiovasc Surg. 2004; 127:1158-65.

2. Koch CG, Khandwala F, Nussmeier N, Blackstone EH. Gender and outcomes after coronary artery bypass grafting: a propensity-matched comparison. J Thorac Cardiovasc Surg. 2003;126:2032-43.

3. Koch CG, Khandwala F, Nussmeier N, Blackstone EH. Gender profiling in coronary artery bypass grafting. J Thorac Cardiovasc Surg. 2003;126:2044-51.

4. Vaccarino V, Lin ZQ, Kasl SV, Mattera JA, Roumanis SA, Abramson JL, et al. Gender differences in recovery after coronary artery bypass surgery. J Am Coll Cardiol. 2003;41:307-14. 
5. Blankstein R, Ward RP, Arnsdorf M, Jones B, Lou YB, Pine M. Female gender is an independent predictor of operative mortality after coronary artery bypass graft surgery: contemporary analysis of 31 Midwestern hospitals. Circulation. 2005; 112:I323-7.

6. Mickleborough LL, Takagi Y, Maruyama H, Sun Z, Mohamed S. Is sex a factor in determining operative risk for aortocoronary bypass graft surgery? Circulation. 1995;92:II80-4

7. Sauerbrei W, Schumacher M. A bootstrap resampling procedure for model building: application to the Cox regression model. Stat Med. 1992;11:2093-109.

8. Blackstone EH, Naftel DC, Turner ME Jr. The decomposition of time-varying hazard into phases, each incorporating a separate stream of concomitant information. J Am Stat Assoc. 1986;81:615-24.

9. Rubin DB. Multiple Imputation for Non-Response in Surveys. New York: Wiley; 1987.

10. Saxena A, Dinh D, Smith JA, Shardey G, Reid CM, Newcomb AE. Sex differences in outcomes following isolated coronary artery bypass graft surgery in Australian patients: analysis of the Australasian Society of Cardiac and Thoracic Surgeons cardiac surgery database. Eur J Cardiothorac Surg. 2012; 41:755-62.

11. Abramov D, Tamariz MG, Sever JY, Christakis GT, Bhatnagar G, Heenan AL, et al. The influence of gender on the outcome of coronary artery bypass surgery. Ann Thorac Surg. 2000;70:800-5; discussion 806.

12. Aldea GS, Gaudiani JM, Shapira OM, Jacobs AK, Weinberg J, Cupples AL, et al. Effect of gender on postoperative outcomes and hospital stays after coronary artery bypass grafting. Ann Thorac Surg. 1999;67:1097-103.

13. Sharoni E, Kogan A, Medalion B, Stamler A, Snir E, Porat E. Is gender an independent risk factor for coronary bypass grafting? Thorac Cardiovasc Surg. 2009; 57:204-8.

14. Hlatky MA, Boothroyd DB, Reitz BA, Shilane DA, Baker LC, Go AS. Adoption and effectiveness of internal mammary artery grafting in coronary artery bypass surgery among Medicare beneficiaries. J Am Coll Cardiol. 2014; 63:33-9.

15. Hammar N, Sandberg E, Larsen FF, Ivert T. Comparison of early and late mortality in men and women after isolated coronary artery bypass graft surgery in Stockholm, Sweden, 1980 to 1989. J Am Coll Cardiol. 1997;29:659-64.

16. Rahimtoola SH, Bennett AJ, Grunkemeier GL, Block P, Starr A. Survival at 15 to 18 years after coronary bypass surgery for angina in women. Circulation. 1993; 88:II71-8.

17. Koch CG, Weng YS, Zhou SX, Savino JS, Mathew JP, Hsu PH, et al. Prevalence of risk factors, and not gender per se, determines short- and long-term survival after coronary artery bypass surgery. J Cardiothorac Vasc Anesth. 2003;17:585-93.

18. Ahmed WA, Tully PJ, Knight JL, Baker RA. Female sex as an independent predictor of morbidity and survival after isolated coronary artery bypass grafting. Ann Thorac Surg. 2011;92:59-67.

19. Vaccarino V, Lin ZQ, Kasl SV, Mattera JA, Roumanis SA, Abramson JL, et al. Sex differences in health status after coronary artery bypass surgery. Circulation. 2003; 108:2642-7.

20. Guru V, Fremes SE, Austin PC, Blackstone EH, Tu JV. Gender differences in outcomes after hospital discharge from coronary artery bypass grafting. Circulation. 2006;113:507-16

21. Koch CG, Khandwala F, Cywinski JB, Ishwaran H, Estafanous FG, Loop FD, et al. Health-related quality of life after coronary artery bypass grafting: a gender analysis using the Duke Activity Status Index. J Thorac Cardiovasc Surg. 2004; 128:284-95.
22. Kurlansky PA, Traad EA, Galbut DL, Singer S, Zucker M, Ebra G. Coronary bypass surgery in women: a long-term comparative study of quality of life after bilateral internal mammary artery grafting in men and women. Ann Thorac Surg. 2002; 74:1517-25.

23. Scott R, Blackstone EH, McCarthy PM, Lytle BW, Loop FD, White JA, et al. Isolated bypass grafting of the left internal thoracic artery to the left anterior descending coronary artery: late consequences of incomplete revascularization. $J$ Thorac Cardiovasc Surg. 2000;120:173-84.

24. Mohr FW, Rastan AJ, Serruys PW, Kappetein AP, Holmes DR, Pomar JL, et al Complex coronary anatomy in coronary artery bypass graft surgery: impact of complex coronary anatomy in modern bypass surgery? Lessons learned from the SYNTAX trial after two years. J Thorac Cardiovasc Surg. 2011;141: 130-40.

25. Cameron AA, Green GE, Brogno DA, Thornton J. Internal thoracic artery grafts: 20-year clinical follow-up. J Am Coll Cardiol. 1995;25:188-92.

26. Lytle BW, Blackstone EH, Sabik JF, Houghtaling P, Loop FD Cosgrove DM. The effect of bilateral internal thoracic artery grafting on survival during 20 postoperative years. Ann Thorac Surg. 2004;78: 2005-14; discussion -14.

27. Muneretto C, Bisleri G, Negri A, Manfredi J, Metra M, Nodari S, et al. Total arterial myocardial revascularization with composite grafts improves results of coronary surgery in elderly: a prospective randomized comparison with conventional coronary artery bypass surgery. Circulation. 2003;108(Suppl 1): II29-33.

28. Tranbaugh RF, Dimitrova KR, Friedmann P, Geller CM, Harris LJ, Stelzer P, et al. Radial artery conduits improve long-term survival after coronary artery bypass grafting. Ann Thorac Surg. 2010;90:1165-72.

29. Douglas JS Jr, King SB III, Jones EL, Craver JM, Bradford JM, Hatcher CR Jr. Reduced efficacy of coronary bypass surgery in women. Circulation. 1981;64: II11-6.

30. Roberts CS, Roberts WC. Cross-sectional area of the proximal portions of the three major epicardial coronary arteries in 98 necropsy patients with different coronary events. Relationship to heart weight, age and sex. Circulation. 1980; 62:953-9.

31. O'Connor NJ, Morton JR, Birkmeyer JD, Olmstead EM, O'Connor GT. Effect of coronary artery diameter in patients undergoing coronary bypass surgery. Northern New England Cardiovascular Disease Study Group. Circulation. 1996;93: 652-5.

32. Sheifer SE, Canos MR, Weinfurt KP, Arora UK, Mendelsohn FO, Gersh BJ, et al Sex differences in coronary artery size assessed by intravascular ultrasound. Am Heart J. 2000;139:649-53.

33. Fisher LD, Kennedy JW, Davis KB, Maynard C, Fritz JK, Kaiser G, et al. Association of sex, physical size, and operative mortality after coronary artery bypass in the Coronary Artery Surgery Study (CASS). J Thorac Cardiovasc Surg. 1982 84:334-41.

34. Blasberg JD, Schwartz GS, Balaram SK. The role of gender in coronary surgery Eur J Cardiothorac Surg. 2011;40:715-21.

35. Kyriakidis M, Petropoulakis P, Androulakis A, Antonopoulos A, Apostolopoulos T, Barbetseas J, et al. Sex differences in the anatomy of coronary artery disease. J Clin Epidemiol. 1995;48:723-30.

Key Words: coronary artery bypass grafting, sex, survival, cardiac surgery 


\section{APPENDIX E1. VARIABLES CONSIDERED IN ANALYSES \\ Demographics}

Age (y), sex, race, weight $(\mathrm{kg})$, height $(\mathrm{cm})$, weight/height ratio, body surface area $\left(\mathrm{m}^{2}\right)$, body mass index $\left(\mathrm{kg} \cdot \mathrm{m}^{-2}\right)$

\section{Acuity}

New York Heart Association functional class (I-IV), emergency operation

\section{Cardiac Comorbidity}

Previous myocardial infarction, atrial fibrillation or flutter, complete heart block or pacer, heart failure

\section{Noncardiac Comorbidity}

Peripheral arterial disease, carotid disease, hypertension, chronic obstructive pulmonary disease, history of smoking, prior stroke, bilirubin $\left(\mathrm{mg} \cdot \mathrm{dL}^{-1}\right)$, cholesterol $\left(\mathrm{mg} \cdot \mathrm{dL}^{-1}\right)$, treated diabetes, triglycerides $\left(\mathrm{mg} \cdot \mathrm{dL}^{-1}\right)$, creatinine $\left(\mathrm{mg} \cdot \mathrm{dL}^{-1}\right)$, blood urea nitrogen $\left(\mathrm{mg} \cdot \mathrm{dL}^{-1}\right)$, hematocrit $(\%)$, high-density lipoprotein cholesterol $\left(\mathrm{mg} \cdot \mathrm{dL}^{-1}\right)$, low-density lipoprotein cholesterol $\left(\mathrm{mg} \cdot \mathrm{dL}^{-1}\right)$

\section{Ventricular Function}

Left ventricular dysfunction (none, mild, mild to moderate, moderate, moderate to severe, severe)

\section{Coronary Artery Disease}

Number of systems diseased $(\geq 50 \%$ stenosis $)$, maximum left main trunk (LMT) stenosis, LMT disease $(0 \%, \geq 70 \%$, and $\geq 50 \%$ stenosis $)$, maximum left anterior descending coronary artery (LAD) stenosis, LAD system disease $(0 \%, \geq 70 \%$, and $\geq 50 \%$ stenosis), maximum left circumflex coronary artery (LCx) stenosis, LCx system disease $(0 \%, \geq 70 \%$, and $\geq 50 \%$ stenosis $)$, maximum right coronary artery (RCA) stenosis, RCA system disease $(0 \%, \geq 70 \%$, and $\geq 50 \%$ stenosis $)$

\section{Blood Product Use}

Any intraoperative or preoperative blood products given.

\section{Procedure}

Number of internal thoracic artery (ITA) grafts (none, single, bilateral), incomplete revascularization (based on $\geq 50 \%$ stenosis). Conduits used: arterial grafts, only arterial grafts, gastroepiploic or inferior epigastric artery, ITA, free ITA, in situ ITA, left ITA, right ITA, radial artery, saphenous vein, other conduit. Graft location: LAD diagonals, LAD (including LMT), LCx territory, RCA territory.

\section{Support}

Cardiopulmonary bypass (off-pump)

\section{Experience}

Date of operation (years since January 1, 1972) 

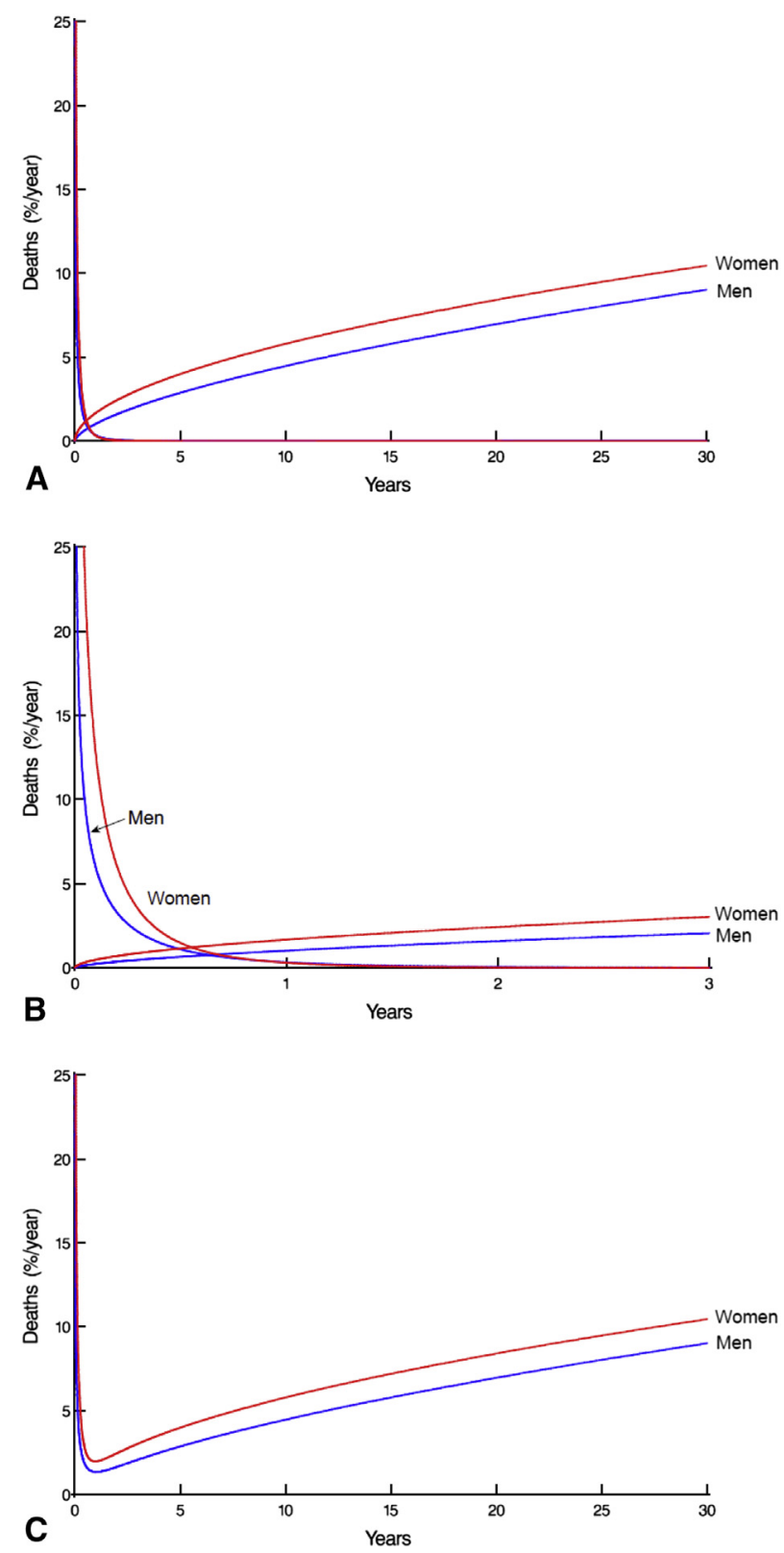

FIGURE E1. Temporal decomposition of instantaneous risk (hazard) of death for women and men. A, Individual hazard phases, showing a rapidly declining early phase and a late rising phase. Concomitant information shrinks or expands the area under the early hazard phase and tilts the late hazard phase. B, As in A, but on expanded horizontal scale. C, Hazard phases added. 

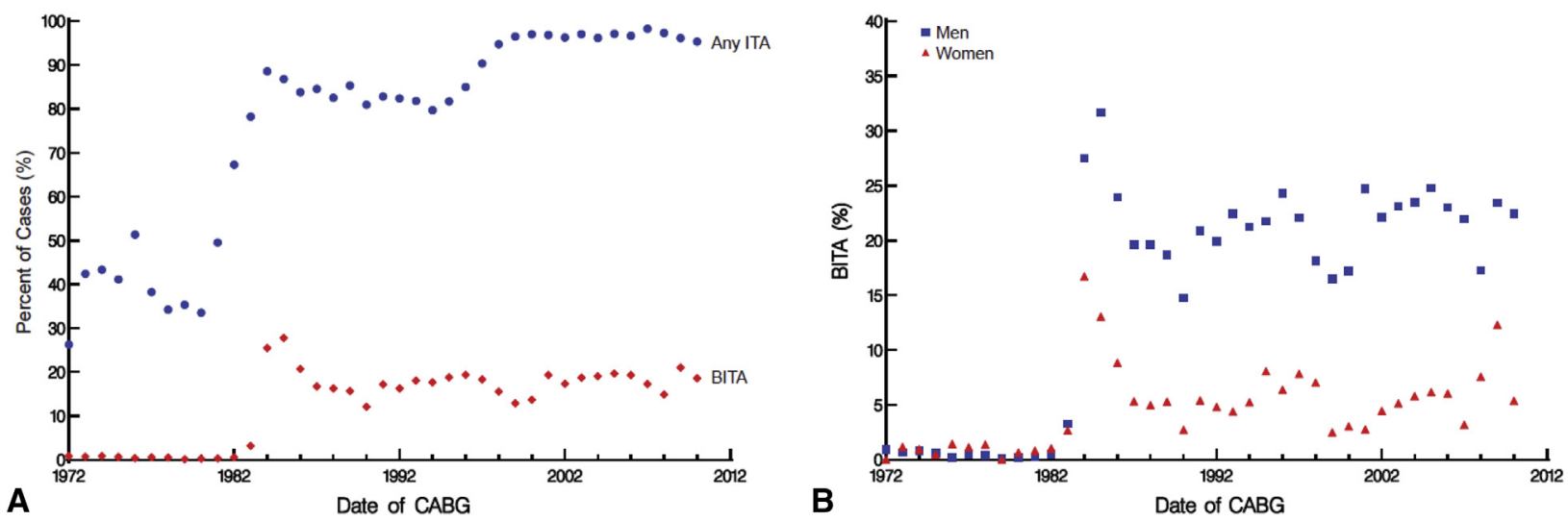

FIGURE E2. Use of ITA grafting by operative year. A, Use of any ITA graft accelerated in the early 1980s, and use of BITA grafting increased at that time, but on average has remained about $20 \%$ of cases. B, BITA grafting was more common in men than women throughout the study period. ITA, Internal thoracic artery; BITA, bilateral internal thoracic artery; $C A B G$, coronary artery bypass grafting.
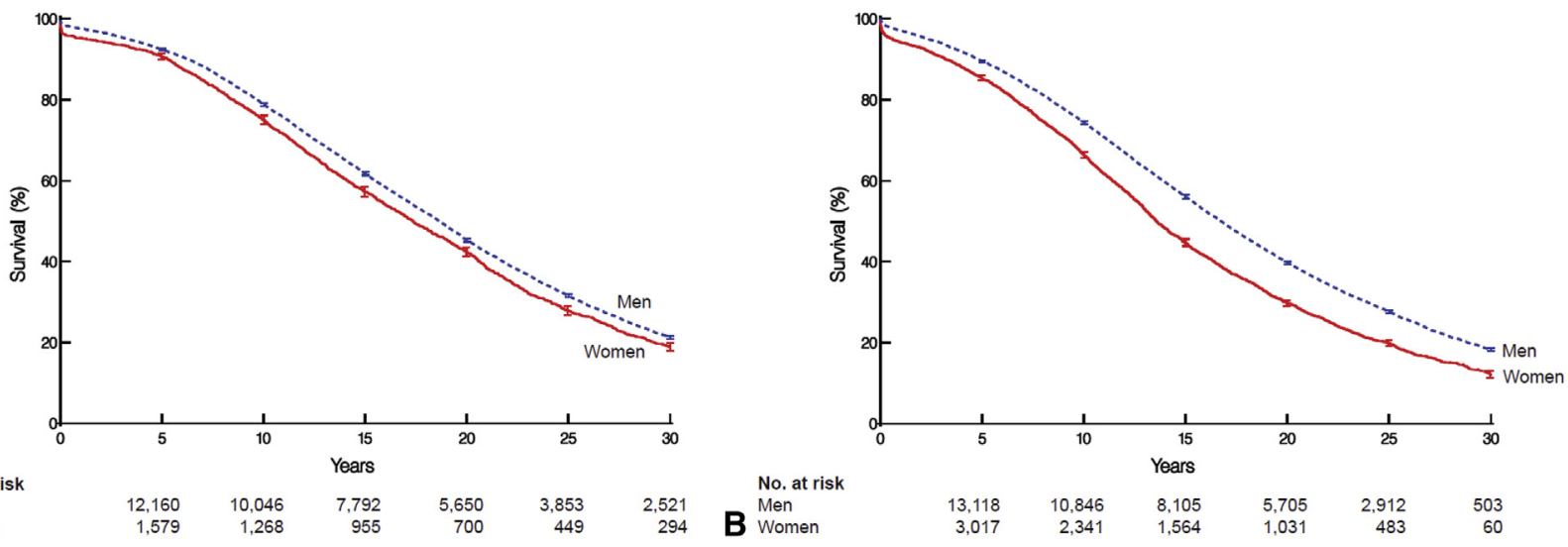

A $\begin{aligned} & \text { No. at risk } \\ & \text { Women }\end{aligned}$
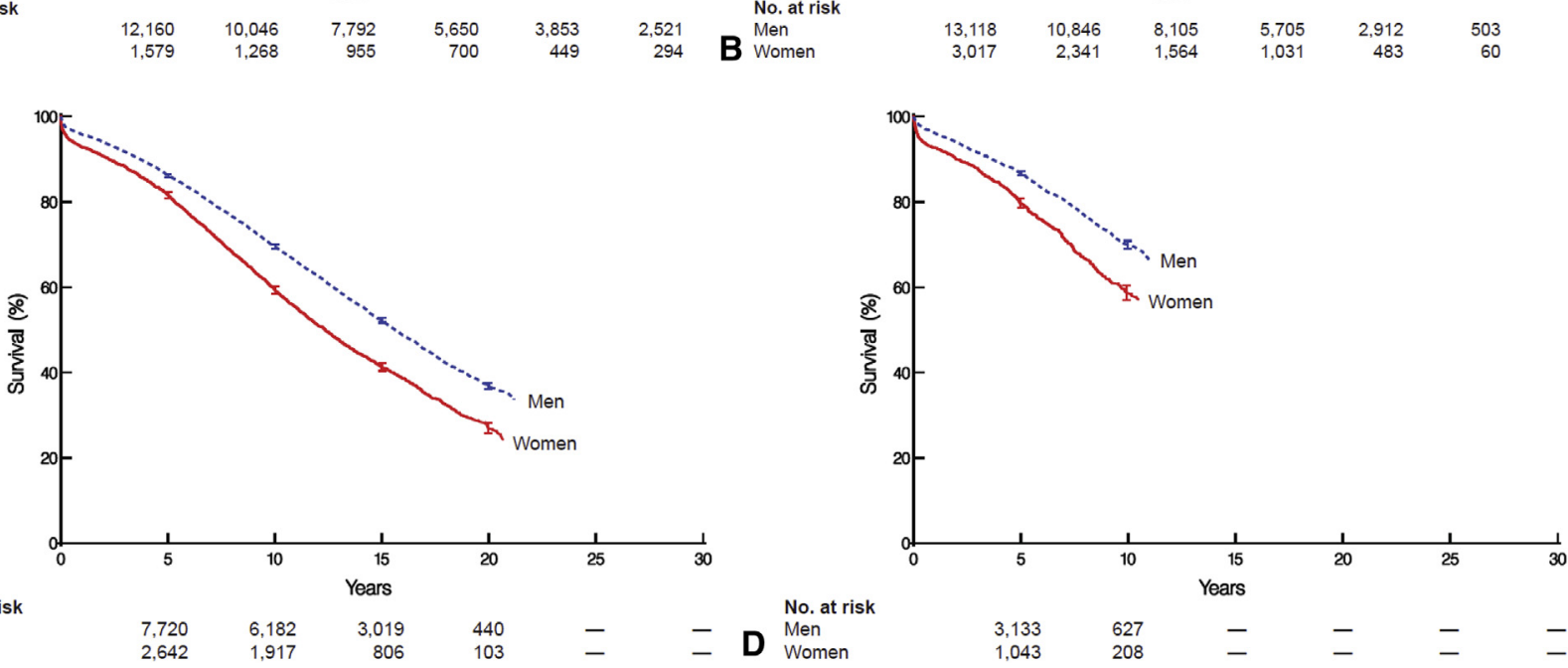

C ${ }_{\text {Wemen }}^{\text {No. at risk }}$

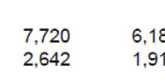

3,019
806

440
103

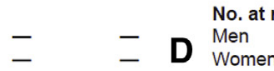

3,133
1,043

FIGURE E3. Persistence of risk-unadjusted survival for women and men after coronary artery bypass grafting. Kaplan-Meier estimates, with $68 \%$ confidence limits shown at 5-year intervals. A, 1970s. B, 1980s. C, 1990s. D, 2000s. 

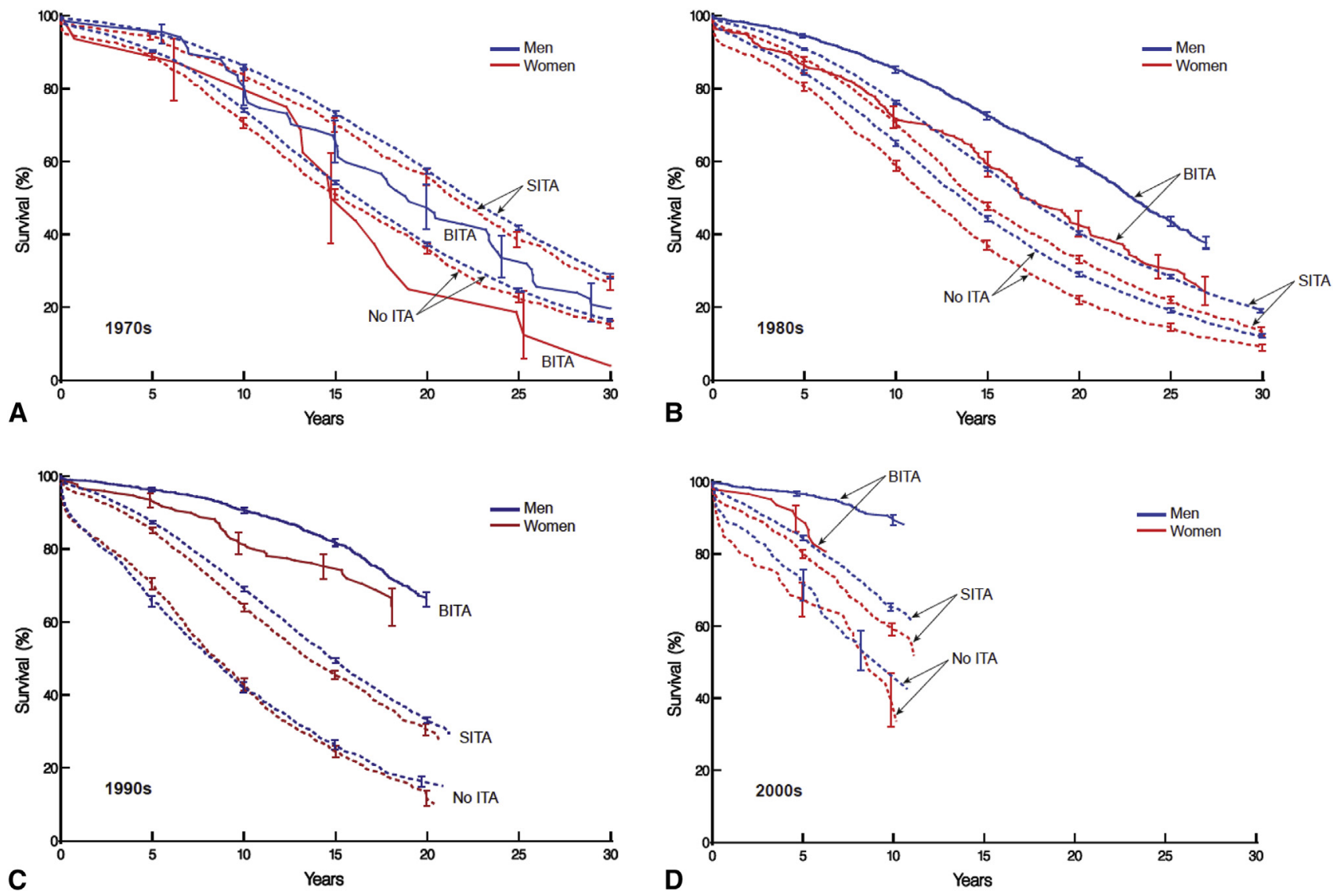

FIGURE E4. Survival in men and women according to revascularization strategy across the decades. Format is as in Figure E3. A, 1970s. B, 1980s. C, 1990s. D, 2000s. SITA, Single internal thoracic artery graft; ITA, internal thoracic artery graft; BITA, Bilateral internal thoracic artery graft. 

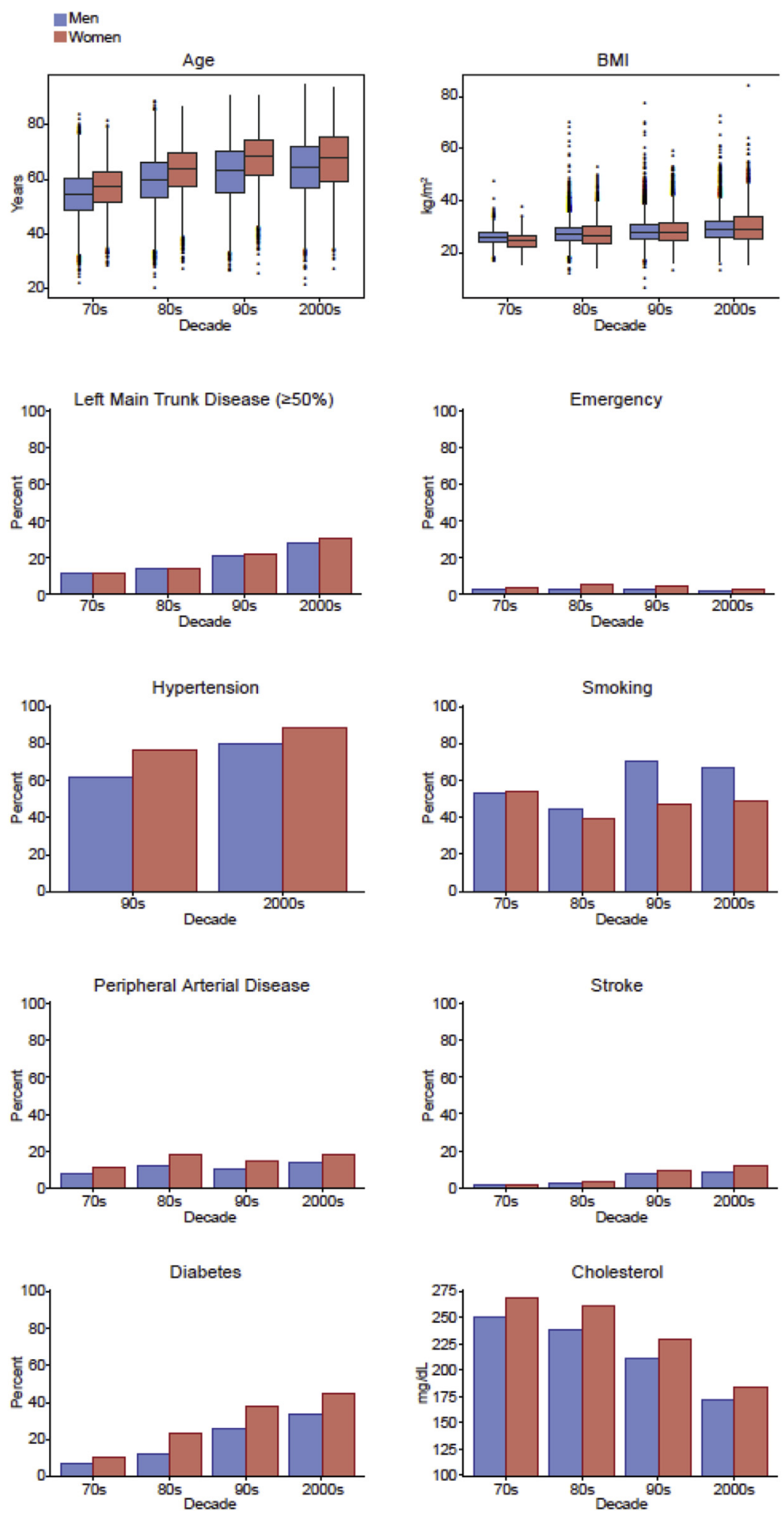

FIGURE E5. Temporal trend in patient demographics and comorbidities. Percentages by decade are depicted. Left-hand blue bars represent prevalences in men and right-hand red bars those in women. For age and BMI, box includes 25th and 75th percentiles, horizontal bar within box is the median, whiskers encompass values within 1.5 of IQR, and individual dots are extreme values. BMI, Body mass index. 
TABLE E1. Risk factors for hospital mortality

\begin{tabular}{|c|c|c|}
\hline Risk factor & Estimate $\pm \mathrm{SE}$ & $\boldsymbol{P}$ \\
\hline \multicolumn{3}{|l|}{ Demographics } \\
\hline Female & $0.59 \pm 0.081$ & $<.0001$ \\
\hline Older age* & $0.58 \pm 0.059$ & $<.0001$ \\
\hline Lower BMI ${ }^{\dagger}$ & $0.26 \pm 0.107$ & .01 \\
\hline \multicolumn{3}{|l|}{ Acuity } \\
\hline NYHA functional class II & $-0.33 \pm 0.089$ & .0002 \\
\hline Emergency operation & $1.7 \pm 0.103$ & $<.0001$ \\
\hline \multicolumn{3}{|l|}{ Coronary artery disease } \\
\hline Left main trunk stenosis $\geq 70 \%$ & $0.54 \pm 0.108$ & $<.0001$ \\
\hline Number of systems diseased $\ddagger$ & $0.32 \pm 0.063$ & $<.0001$ \\
\hline \multicolumn{3}{|l|}{ Cardiac comorbidity } \\
\hline Heart failure & $0.57 \pm 0.106$ & $<.0001$ \\
\hline Previous myocardial infarction & $0.31 \pm 0.078$ & $<.0001$ \\
\hline Greater left ventricular dysfunction & $0.12 \pm 0.031$ & $<.0001$ \\
\hline \multicolumn{3}{|l|}{ Noncardiac comorbidity } \\
\hline Peripheral arterial disease & $0.46 \pm 0.089$ & $<.0001$ \\
\hline Stroke & $0.44 \pm 0.13$ & .0007 \\
\hline Pharmacologically treated diabetes & $0.29 \pm 0.091$ & .002 \\
\hline Higher creatinine $\S$ & $0.73 \pm 0.109$ & $<.0001$ \\
\hline \multicolumn{3}{|l|}{ Procedural } \\
\hline Internal thoracic artery grafting & $-0.86 \pm 0.088$ & $<.0001$ \\
\hline Earlier date of operation $\uparrow$ & $-0.030 \pm 0.0058$ & $<.0001$ \\
\hline Intercept & $-7.8 \pm 0.26$ & $<.0001$ \\
\hline
\end{tabular}


TABLE E2. Incremental risk factors for time-related death, stratified by sex: early hazard phase

\begin{tabular}{|c|c|c|c|c|c|c|c|c|}
\hline \multirow[b]{2}{*}{ Risk factor } & \multicolumn{3}{|c|}{ Men } & \multicolumn{3}{|c|}{ Women } & \multicolumn{2}{|c|}{ Difference from men } \\
\hline & Coefficient \pm SE & $\boldsymbol{P}$ & $\mathbf{R}(\%)^{*}$ & Coefficient \pm SE & $\boldsymbol{P}$ & $\mathbf{R}(\%) *$ & Coefficient $\pm \mathrm{SE}$ & $\boldsymbol{P}$ \\
\hline \multicolumn{9}{|l|}{ Demographics } \\
\hline Older age $\dagger$ & $0.55 \pm 0.055$ & $<.0001$ & 100 & $0.35 \pm 0.074$ & $<.0001$ & 100 & $-0.19 \pm 0.089$ & .04 \\
\hline Lower BMI $\ddagger$ & $0.26 \pm 0.12$ & .03 & 98 & $0.20 \pm 0.15$ & .19 & 23 & $-0.048 \pm 0.19$ & .8 \\
\hline \multicolumn{9}{|l|}{ Acuity } \\
\hline \multicolumn{9}{|l|}{ NYHA functional class } \\
\hline II & $-0.31 \pm 0.096$ & .002 & 98 & $-0.58 \pm 0.15$ & $<.0001$ & 99 & $-0.26 \pm 0.17$ & .13 \\
\hline III/IV & $-0.19 \pm 0.088$ & .03 & 98 & $-0.26 \pm 0.12$ & .03 & 99 & $-0.07 \pm 0.15$ & .6 \\
\hline Emergency operation & $1.24 \pm 0.11$ & $<.0001$ & 100 & $1.13 \pm 0.14$ & $<.0001$ & 100 & $-0.18 \pm 0.17$ & .3 \\
\hline \multicolumn{9}{|l|}{ Coronary artery disease $\S$} \\
\hline LMT & $0.46 \pm 0.096$ & $<.0001$ & 98 & $0.21 \pm 0.14$ & .14 & 15 & $-0.26 \pm 0.17$ & .14 \\
\hline LAD & $0.27 \pm 0.10$ & .008 & 98 & $0.11 \pm 0.14$ & .4 & 19 & $-0.18 \pm 0.17$ & .3 \\
\hline $\mathrm{LCx}$ & $0.32 \pm 0.09$ & .0006 & 98 & $0.44 \pm 0.11$ & $<.0001$ & 90 & $0.12 \pm 0.14$ & .4 \\
\hline \multicolumn{9}{|l|}{ Cardiac comorbidity } \\
\hline Atrial fibrillation or flutter & $0.72 \pm 0.17$ & $<.0001$ & 97 & $0.35 \pm 0.32$ & .3 & 23 & $-0.26 \pm 0.35$ & .5 \\
\hline Heart failure & $0.41 \pm 0.10$ & $<.0001$ & 97 & $0.49 \pm 0.12$ & $<.0001$ & 96 & $0.11 \pm 0.16$ & .4 \\
\hline Previous myocardial infarction & $0.19 \pm 0.073$ & .007 & 78 & $0.059 \pm 0.099$ & .6 & 16 & $-0.13 \pm 0.12$ & .3 \\
\hline Greater LV dysfunction & $0.13 \pm 0.030$ & $<.0001$ & 75 & $0.12 \pm 0.037$ & .002 & 40 & $-0.012 \pm 0.043$ & .8 \\
\hline \multicolumn{9}{|l|}{ Noncardiac comorbidity } \\
\hline Peripheral arterial disease & $0.48 \pm 0.082$ & $<.0001$ & 100 & $0.38 \pm 0.11$ & .0007 & 89 & $-0.087 \pm 0.14$ & .5 \\
\hline Stroke & $0.69 \pm 0.11$ & $<.0001$ & 100 & $0.19 \pm 0.16$ & .2 & 14 & $-0.49 \pm 0.19$ & .009 \\
\hline History of smoking & $0.27 \pm 0.074$ & .0002 & 95 & $-0.061 \pm 0.10$ & .5 & 9 & $-0.28 \pm 0.12$ & .02 \\
\hline Higher creatinine $q$ & $0.09 \pm 0.058$ & .12 & 33 & $0.19 \pm 0.081$ & .02 & 51 & $0.071 \pm 0.097$ & .5 \\
\hline Lower cholesterol $\|$ & $0.32 \pm 0.13$ & .01 & 39 & $0.49 \pm 0.17$ & .008 & 80 & $0.22 \pm 0.23$ & .3 \\
\hline Lower hematocrit\# & $-1.01 \pm 0.16$ & $<.0001$ & 78 & $-0.64 \pm 0.31$ & .04 & 12 & $0.37 \pm 0.31$ & .2 \\
\hline \multicolumn{9}{|l|}{ Revascularization strategy } \\
\hline \multicolumn{9}{|l|}{ Incomplete revascularization } \\
\hline With $\geq 50 \%$ stenosis & $0.25 \pm 0.074$ & .0009 & 96 & $0.16 \pm 0.11$ & .13 & 89 & $-0.097 \pm 0.13$ & .4 \\
\hline \multicolumn{9}{|l|}{ ITA graft } \\
\hline Single & $-0.71 \pm 0.078$ & $<.0001$ & 100 & $-0.57 \pm 0.11$ & $<.0001$ & 100 & $0.15 \pm 0.13$ & .2 \\
\hline Bilateral & $-0.92 \pm 0.18$ & $<.0001$ & 100 & $-0.63 \pm 0.32$ & .05 & 100 & $0.25 \pm 0.37$ & .5 \\
\hline Bilateral vs single & $-0.21 \pm 0.17$ & .2 & 100 & $-0.058 \pm 0.31$ & .8 & 100 & $0.14 \pm 0.36$ & .7 \\
\hline No graft vs single & $0.70 \pm 0.078$ & $<.0001$ & 100 & $0.57 \pm 0.11$ & $<.0001$ & 100 & $-0.16 \pm 0.13$ & .2 \\
\hline \multicolumn{9}{|l|}{ Support } \\
\hline Cardiopulmonary bypass (off-pump) & $-0.028 \pm 0.19$ & .9 & 15 & $0.25 \pm 0.20$ & .2 & 9 & $0.29 \pm 0.28$ & .3 \\
\hline \multicolumn{9}{|l|}{ Blood product use } \\
\hline $\begin{array}{l}\text { Any intra- or postoperative } \\
\text { blood product }\end{array}$ & $0.69 \pm 0.16$ & .0006 & 100 & $0.46 \pm 0.28$ & .13 & 33 & $-0.27 \pm 0.28$ & .3 \\
\hline
\end{tabular}

Missing value flags for cholesterol and creatinine are used in the model to adjust for block missing data. SE, Standard error; $R$, reliability; $B M I$, body mass index; $N Y H A$, New York Heart Association; $L M T$, left main trunk; $L A D$, left anterior descending coronary artery; $L C x$, left circumflex coronary artery; $L V$, left ventricular; $I T A$, internal thoracic artery. $*$ Percent of times factor appeared in 500 bootstrap models. $\dagger$ Exp(age/50), exponential transformation. $\ddagger(25 / \mathrm{BMI})^{2}$, inverse squared transformation. $\S \geq 70 \%$ stenosis.

\Log(creatinine), logarithmic transformation. \|(230/cholesterol), inverse transformation. \#Log(hematocrit), logarithmic transformation. 
TABLE E3. Incremental risk factors for time-related death, stratified by sex: late hazard phase

\begin{tabular}{|c|c|c|c|c|c|c|c|c|}
\hline \multirow[b]{2}{*}{ Risk factor } & \multicolumn{3}{|c|}{ Men } & \multicolumn{3}{|c|}{ Women } & \multicolumn{2}{|c|}{ Difference from men } \\
\hline & Coefficient $\pm S E$ & $P$ & $\mathbf{R}(\%)^{*}$ & Coefficient $\pm S E$ & $\boldsymbol{P}$ & $\mathbf{R}(\%) *$ & Coefficient \pm SE & $P$ \\
\hline \multicolumn{9}{|l|}{ Demographics } \\
\hline \multicolumn{9}{|l|}{ Older age } \\
\hline Age & $0.025 \pm 0.0052$ & $<.0001$ & 100 & $0.0046 \pm 0.011$ & .7 & 100 & $-0.022 \pm 0.012$ & .06 \\
\hline Age $\dagger$ & $0.40 \pm 0.078$ & $<.0001$ & 100 & $0.55 \pm 0.15$ & .0002 & 100 & $0.21 \pm 0.17$ & .2 \\
\hline \multicolumn{9}{|l|}{ Lower and higher BMI } \\
\hline BMI & $0.012 \pm 0.0032$ & .0003 & 100 & $0.02 \pm 0.0065$ & .007 & 94 & $0.0088 \pm 0.0071$ & .2 \\
\hline $\mathrm{BMI}_{\ddagger}^{\dagger}$ & $0.083 \pm 0.068$ & .2 & 100 & $0.19 \pm 0.094$ & .04 & 94 & $0.11 \pm 0.12$ & .4 \\
\hline \multicolumn{9}{|l|}{ Race } \\
\hline White & $0.074 \pm 0.038$ & .05 & 100 & $0.059 \pm 0.059$ & .3 & 33 & $-0.028 \pm 0.071$ & .7 \\
\hline \multicolumn{9}{|l|}{ Acuity } \\
\hline NYHA functional class III/IV & $0.071 \pm 0.013$ & $<.0001$ & 100 & $0.042 \pm 0.026$ & .11 & 95 & $-0.035 \pm 0.029$ & .2 \\
\hline Emergency surgery & $-0.11 \pm 0.044$ & .013 & 76 & $-0.15 \pm 0.073$ & .04 & 59 & $-0.039 \pm 0.086$ & .6 \\
\hline \multicolumn{9}{|l|}{ Coronary artery disease $\S$} \\
\hline LMT & $0.12 \pm 0.018$ & $<.0001$ & 100 & $0.046 \pm 0.038$ & .2 & 41 & $-0.066 \pm 0.042$ & .12 \\
\hline LAD & $0.13 \pm 0.024$ & $<.0001$ & 100 & $0.073 \pm 0.045$ & .11 & 14 & $-0.058 \pm 0.051$ & .3 \\
\hline $\mathrm{LCx}$ & $0.13 \pm 0.016$ & $<.0001$ & 100 & $0.15 \pm 0.031$ & $<.0001$ & 99 & $0.019 \pm 0.035$ & .6 \\
\hline RCA & $0.09 \pm 0.017$ & $<.0001$ & 100 & $0.094 \pm 0.034$ & .006 & 99 & $0.0026 \pm 0.038$ & $>.9$ \\
\hline \multicolumn{9}{|l|}{ Cardiac comorbidity } \\
\hline Atrial fibrillation or flutter & $0.43 \pm 0.06$ & $<.0001$ & 100 & $0.50 \pm 0.12$ & $<.0001$ & 99 & $0.076 \pm 0.13$ & .6 \\
\hline Heart failure & $0.37 \pm 0.031$ & $<.0001$ & 100 & $0.32 \pm 0.045$ & $<.0001$ & 100 & $-0.036 \pm 0.055$ & .5 \\
\hline Previous myocardial infarction & $0.15 \pm 0.013$ & $<.0001$ & 100 & $0.11 \pm 0.027$ & $<.0001$ & 99 & $-0.03 \pm 0.03$ & .3 \\
\hline Greater LV dysfunction & $0.11 \pm 0.0079$ & $<.0001$ & 100 & $0.071 \pm 0.014$ & $<.0001$ & 97 & $-0.027 \pm 0.015$ & .08 \\
\hline \multicolumn{9}{|l|}{ Noncardiac comorbidity } \\
\hline Peripheral arterial disease & $0.38 \pm 0.02$ & $<.0001$ & 100 & $0.37 \pm 0.034$ & $<.0001$ & 100 & $-0.0046 \pm 0.040$ & $>.9$ \\
\hline Stroke & $0.26 \pm 0.034$ & $<.0001$ & 100 & $0.30 \pm 0.055$ & $<.0001$ & 100 & $0.058 \pm 0.064$ & .4 \\
\hline Pharmacologically treated diabetes & $0.42 \pm 0.02$ & $<.0001$ & 100 & $0.51 \pm 0.032$ & $<.0001$ & 100 & $0.12 \pm 0.037$ & .00 \\
\hline History of smoking & $0.24 \pm 0.014$ & $<.0001$ & 100 & $0.23 \pm 0.028$ & $<.0001$ & 100 & $0.0074 \pm 0.03$ & .8 \\
\hline Higher creatinine $\llbracket$ & $0.075 \pm 0.010$ & $<.0001$ & 85 & $0.073 \pm 0.025$ & .007 & 100 & $-0.018 \pm 0.025$ & .5 \\
\hline Lower cholesterol $\|$ & $0.0038 \pm 0.013$ & .8 & 16 & $0.034 \pm 0.018$ & .06 & 100 & $0.039 \pm 0.024$ & .10 \\
\hline Higher triglycerides & $0.046 \pm 0.013$ & .001 & 100 & $0.059 \pm 0.025$ & .03 & 98 & $0.016 \pm 0.027$ & .6 \\
\hline \multicolumn{9}{|l|}{ Revascularization strategy } \\
\hline \multicolumn{9}{|l|}{ Incomplete revascularization } \\
\hline With $\geq 50 \%$ stenosis & $0.081 \pm 0.015$ & $<.0001$ & 98 & $0.077 \pm 0.032$ & .02 & 48 & $-0.0014 \pm 0.035$ & $>.9$ \\
\hline \multicolumn{9}{|l|}{ ITA graft } \\
\hline Single & $-0.20 \pm 0.015$ & $<.0001$ & 100 & $-0.17 \pm 0.03$ & $<.0001$ & 100 & $0.032 \pm 0.033$ & .3 \\
\hline Bilateral & $-0.51 \pm 0.031$ & $<.0001$ & 100 & $-0.29 \pm 0.075$ & .0001 & 100 & $0.23 \pm 0.081$ & .00 \\
\hline Bilateral vs single & $-0.31 \pm 0.029$ & $<.0001$ & 100 & $-0.12 \pm 0.072$ & .10 & 100 & $0.20 \pm 0.078$ & .01 \\
\hline No graft vs single & $0.20 \pm 0.015$ & $<.0001$ & 100 & $0.17 \pm 0.030$ & $<.0001$ & 100 & $-0.032 \pm 0.029$ & .3 \\
\hline \multicolumn{9}{|l|}{ Support } \\
\hline Cardiopulmonary bypass (off-pump) & $-0.083 \pm 0.061$ & .17 & 9 & $-0.0072 \pm 0.082$ & $>.9$ & 6 & $0.11 \pm 0.10$ & .3 \\
\hline \multicolumn{9}{|l|}{ Blood product use } \\
\hline $\begin{array}{l}\text { Any intra- or postoperative } \\
\text { blood product }\end{array}$ & $0.069 \pm 0.024$ & .006 & 89 & $0.051 \pm 0.053$ & .3 & 7 & $-0.030 \pm 0.059$ & .6 \\
\hline
\end{tabular}

Missing value flags for cholesterol and creatinine are used in the model to adjust for block missing data. SE, Standard error; $R$, reliability; $B M I$, body mass index; $N Y H A$, New York Heart Association; $L M T$, left main trunk; $L A D$, left anterior descending coronary artery; $L C x$, left circumflex coronary artery; $R C A$, right coronary artery; $L V$, left ventricular; $I T A$, internal thoracic artery. *Percent of times factor appeared in 500 bootstrap models. $\dagger$ Exp(age/50), exponential transformation. $\ddagger(25 / \text { BMI })^{2}$, inverse squared transformation. $\S \geq 70 \%$ stenosis. $\left\lceil\log (\right.$ creatinine $)$, logarithmic transformation. $\|(230 / \text { cholesterol })^{2}$, inverse squared transformation. 
TABLE E4. In-hospital outcomes stratified by era: 1972 to 2000

\begin{tabular}{|c|c|c|c|c|c|}
\hline \multirow[b]{2}{*}{ Outcome } & \multicolumn{2}{|c|}{ Men $(n=41,090)$} & \multicolumn{2}{|c|}{ Women $(\mathbf{n}=9083)$} & \multirow[b]{2}{*}{$\boldsymbol{P}$} \\
\hline & n* & No. $(\%)$ & n* & No. $(\%)$ & \\
\hline Hospital death & 41,090 & $468(1.1)$ & 9083 & $261(2.9)$ & $<.0001$ \\
\hline Atrial fibrillation & 40,695 & $4462(11)$ & 8985 & $1182(13)$ & $<.0001$ \\
\hline Reoperation for bleeding/tamponade & 41,090 & $1724(4.2)$ & 9083 & $337(3.7)$ & .03 \\
\hline Septicemia & 10,624 & $167(1.6)$ & 3402 & $82(2.4)$ & .001 \\
\hline Deep sternal wound infection & 39,119 & $512(1.3)$ & 8723 & $148(1.7)$ & .005 \\
\hline Permanent stroke & 41,090 & $598(1.5)$ & 9083 & $224(2.5)$ & $<.0001$ \\
\hline Perioperative myocardial infarction & 41,090 & $966(2.4)$ & 9083 & $233(2.6)$ & .2 \\
\hline Renal failure requiring dialysis & 10,624 & $68(0.64)$ & 3402 & $38(1.1)$ & .005 \\
\hline \multicolumn{6}{|l|}{ Length of stay $\dagger$} \\
\hline $\mathrm{ICU}, \mathrm{h}$ & 10,622 & $24 / 24 / 72$ & 3400 & $24 / 24 / 96$ & $<.0001$ \\
\hline Postoperative, $\mathrm{d}$ & 39,967 & 7.0/8.0/11 & 8917 & $6.8 / 8.0 / 12$ & .3 \\
\hline
\end{tabular}

$\overline{I C U}$, Intensive care unit. *Patients with data available. $\dagger 15$ th $/ 50$ th/85th percentiles. Median score test was used to compare medians and Wilcoxon rank-sum test to compare tails of distributions. $P$ values are given for median score test.

TABLE E5. In-hospital outcomes stratified by era: 2000 to 2011

\begin{tabular}{|c|c|c|c|c|c|}
\hline \multirow[b]{2}{*}{ Outcome } & \multicolumn{2}{|c|}{$\operatorname{Men}(n=5844)$} & \multicolumn{2}{|c|}{ Women $(n=1926)$} & \multirow[b]{2}{*}{$\boldsymbol{P}$} \\
\hline & $\mathbf{n}^{*}$ & No. $(\%)$ & $\mathbf{n}^{*}$ & No. $(\%)$ & \\
\hline Hospital death & 5844 & $42(0.72)$ & 1926 & $32(1.7)$ & .0002 \\
\hline Atrial fibrillation & 5766 & $1603(28)$ & 1901 & $446(23)$ & .0002 \\
\hline Reoperation for bleeding/tamponade & 5844 & $134(2.3)$ & 1926 & $49(2.5)$ & .5 \\
\hline Septicemia & 5844 & $98(1.7)$ & 1926 & $44(2.3)$ & .08 \\
\hline Deep sternal wound infection & 5844 & $62(1.1)$ & 1926 & $43(2.2)$ & .0001 \\
\hline Permanent stroke & 5844 & $49(0.84)$ & 1926 & $30(1.6)$ & .006 \\
\hline Perioperative myocardial infarction & 5844 & $11(0.19)$ & 1926 & $7(0.36)$ & .18 \\
\hline Renal failure requiring dialysis & 5844 & $50(0.86)$ & 1926 & 37 (1.9) & .0001 \\
\hline \multicolumn{6}{|l|}{ Length of stay $\dagger$} \\
\hline ICU, h & 5844 & $22 / 27 / 73$ & 1926 & $23 / 31 / 96$ & $<.0001$ \\
\hline Postoperative, $\mathrm{d}$ & 5844 & $4.9 / 6.1 / 9.1$ & 1926 & $5.1 / 6.9 / 11$ & $<.0001$ \\
\hline
\end{tabular}

